The manuscript is a preprint uploaded to EarthArxiv. This preprint has been submitted for publication to Earth and Planetary Science Letters on the 30th of August 2021. Authors encourage downloading the latest manuscript version from EarthArXiv, and welcome comments, feedback and discussions anytime.

Please, feel free to get in contact: utsav@iiiserpune.ac.in

Title: Thrusts control the thermal maturity of accreted sediments

Authors: Utsav Mannu ${ }^{1, *}$, David Fernández-Blanco², Ayumu Miyakawa ${ }^{3}$, Taras Gerya ${ }^{4}$, and Masataka Kinoshita ${ }^{5}$

Affiliations:

${ }^{1}$ Department of Earth and Climate Science, Indian Institute of Science Education and Research, Pune, India

*corresponding author: utsav@iiiserpune.ac.in

${ }^{2}$ Barcelona Center of Subsurface Imaging, Institut de Ciències del Mar (ICM-CSIC), Barcelona, Spain;

${ }^{3}$ Geological Survey of Japan, AIST

${ }^{4}$ Institute of Geophysics, ETH Zurich

${ }^{5}$ Earthquake Research Institute, UTokyo 


\section{Thrusts control the thermal maturity of accreted sediments}

Utsav Mannu ${ }^{1, *}$, David Fernández-Blanco ${ }^{2}$, Ayumu Miyakawa $^{3}$, Taras Gerya ${ }^{4}$, and Masataka Kinoshita ${ }^{5}$

${ }^{1}$ Department of Earth and Climate Science, Indian Institute of Science Education and Research, Pune, India

*corresponding author: utsav@iiiserpune.ac.in

${ }^{2}$ Barcelona Center of Subsurface Imaging, Institut de Ciències del Mar (ICM-CSIC), Barcelona, Spain;

${ }^{3}$ Geological Survey of Japan, AIST

${ }^{4}$ Institute of Geophysics, ETH Zurich

${ }^{5}$ Earthquake Research Institute, UTokyo 


\section{ABSTRACT}

Thermal maturity assessments of hydrocarbon-generation potential and thermal history rarely consider how structures developing during subduction influence the trajectories of accreted sediments. Our thermomechanical models of subduction support that thrusts evolving under variable sedimentation rates and décollement strengths fundamentally influence the trajectory, temperature, and thermal maturity of accreting sediments. This is particularly true for the frontal thrust, which pervasively partitions sediments along a low and a high maturity path. Notably, our findings imply that interpretations of the distribution of thermal maturity cannot be detached from accounts of the length and frequency of thrusts and their controlling factors. Taking these factors into consideration, our approach reduces former inconsistencies between predicted and factual thermal maturity distributions in accretionary wedges and provides a first-order predictive indicator for thermal maturity distribution based on known fault architectures. 


\section{Introduction}

Organic material transforms into coal, oil, and gas at rates primarily controlled by temperature(Quigley and Mackenzie, 1988). This transformation, critical for the hydrocarbon industry, is also useful to study the tectonic and sedimentary evolution of basins and orogens(Tissot et al., 1987; Tissot and Welte, 2013; Waples, 1981). The extent of this transformation in sediments, known as their thermal maturity, can be measured as vitrinite reflectance; this is, the percentage of incident light reflected from the surface of vitrinite particles in those sediments(Burnham and Sweeney, 1989). Thermal maturity has been used to estimate the thermal evolution of igneous intrusions(Bostick and Pawlewicz, 1984) and seismic slip(Rabinowitz et al., 2020), the extent of diagenesis and low-grade metamorphism(Ferreiro Mählmann and Le Bayon, 2016; Totten and Blatt, 1993), porosity and compaction in basin sediments(Schmoker and Gautier, 1988), as well as the geothermal history of accreting material during subduction(Sakaguchi et al., 2011; Underwood et al., 1992; Yamamoto et al., 2017).

Inferences on the geothermal history of subduction margins based on thermal maturity depend on the trajectory followed by the accreting sediments(Miyakawa et al., 2019). As the orogenic wedge evolves, sediments accreting along different paths reach different depths and velocities, and are exposed to different regional peak temperatures. The spatiotemporal evolution of thermal maturity is thus controlled, to a first-order, by the partition of incoming sediments along two end-member pathways; (i) a deeper path leading to elevated thermal maturities, the high thermal-maturity path, and (ii) a shallower path resulting in low thermal maturity, the low thermal-maturity path(Miyakawa et al., 2019). Much remains to be explored regarding how this partition and the general translation of sediments occur inside the wedge, given the conventional assumption that accreting sediments remain at the same relative depth and translate along adjacent "layers" without vertical mixing throughout the tectonic evolution of the wedge(Luján et al., 2010; Willett et al., 1993). This lack of detail on the trajectories followed by wedge sediments reduces the accuracy of geologic inferences derived from thermal maturity. To better 
understand the time-depth paths of their sediments, and thus their thermal maturity, the factors that control the evolution of subduction-accretion systems, like sedimentation, erosion, and décollement strength(Mannu et al., 2016; Simpson, 2010), ought to be considered.

Here, we explore in detail the impact that a realistic account of accretion in a subduction wedge has on the thermal maturity of its sediments. We simulate subduction-accretion using $2 \mathrm{D}$ finite-difference thermomechanical models that incorporate empirical thermal conductivity values from the Nankai accretionary margin. We track the evolution of thermal maturity by computing vitrinite reflectance on markers in the model mesh, as the wedge develops by accretion under different sedimentation rates and décollement strengths. These factors notably alter the trajectories and thermal maturities of incoming sediments. Particularly, thrusts act as sharp thermal maturity boundaries leading to a stack difference in the thermal maturity of sediments that follow similar trajectories and lay nearby but accrete in different thrust blocks.

\section{Methods}

We employ I2VIS, a conservative(Gerya, 2019) finite-difference 2-D thermomechanical subduction-accretion model with visco-plastic/brittle rheology.(Gerya and Yuen, 2003) The code solves the governing equations for conservation of mass, momentum and heat as well as the advection equation with a non-diffusive marker-in-cell scheme(Gerya, 2019) constrained by thermal conductivity values inferred from Nankai accretionary wedge(Sugihara et al., 2014). Our numerical approach has several advantages over earlier modeling attempts to simulate thermal maturity in an accretionary wedge(Miyakawa et al., 2019) such as a more realistic geothermal profile, thermal evolution, and dynamic sediment subduction. The supplementary material contains additional information regarding the governing equations, the modified thermal conductivity formulations, boundary conditions, rheological model, and surface processes. 


\subsection{An improved thermal maturity calculation}

Given that assessments of thermal maturity are inherently reliant on the distribution of temperature inside the wedge, any attempt to model thermal maturity needs a realistic temperature gradient in the wedge. We incorporate this by modifying the thermal conductivity computation for sediments and décollement (see Table 1 and section 1 in the provided supplementary text ) to match the empirical relationship between depth and thermal conductivity, as measured on core samples in the borehole at IODP Site C0002(Sugihara et al., 2014; Tobin et al., 2015).

The model computes the Vitrinite Reflectance (Ro\%) of each marker to estimate the thermal maturity of sediments during the model run. At the start of the model, Ro\% is set to 0.2 in sediment markers, while Ro\% in markers for other rocks, air, and water is undefined. Thereafter, the model computes Ro\% on each marker as a function of temperature $(T)$, time $(t)$, and amount of fixed carbon as a percentage, $f_{c}$ (Suzuki et al., 1993):

$$
\begin{aligned}
& R o=\exp \left(\ln R o_{\text {init }}+3.7 f_{c}\right) \quad(\text { eq. } 1) \\
& f_{c}=0.85\left(1-\exp \left(-A \exp \left(\frac{-E \Delta t}{R T}\right)\right)\right) \quad(\text { eq. 2) } \\
& E=40.7 \ln R o+227 \quad \text { (eq. 3) }
\end{aligned}
$$

Where $R o$ is the vitrinite reflectance, $f c$ is the amount of fixed carbon in percentage, $R o_{\text {init }}$ is the initial vitrinite reflectance $(0.2)$, Ais a frequency factor $\left(1.0 \times 10^{13} / \mathrm{s}\right), R$ is the gas constant, $\Delta t$ is the duration of the calculation interval, and $E$ is the activation energy.

\subsection{Initial model setup}

The modeling domain is $3500 \mathrm{~km}$ wide and $350 \mathrm{~km}$ deep and is discretized into $1284 \times 401$ nodes populated with $\sim 25$ million markers. At the site of accretionary wedge evolution, we assign a significantly 
higher resolution of $130 \mathrm{~m}$ (vertical) $\times 1200 \mathrm{~m}$ (horizontal), which steadily decreases near the boundary of the modelling domain. The simulation consists of an oceanic plate converging with a velocity of $\sim 5 \mathrm{~cm} / \mathrm{yr}$ and subducting beneath continental plate (see Fig.S1). The oceanic plate consists of a 1-km-thick upper oceanic crust and a 7-km-thick lower oceanic crust underlain by a 47-km-thick mantle lithosphere. Displacement along the megathrust, at the contact between subducting oceanic plate and the overriding continental plate, results in a relatively weak basal layer in accretionary wedges across the globe(Byrne and Fisher, 1990). We simulate this configuration at the interplate with a 350-meter-thick décollement below a 1-kilometer-thick sediment layer. The wedge forms above this interphase by accretion of sediments against the continental plate. The continental plate consists of an upper and lower continental crust with thicknesses of $20 \mathrm{~km}$ and $15 \mathrm{~km}$, respectively, and underlain by a mantle lithosphere of $25 \mathrm{~km}$. A weak layer is emplaced at the junction of both plates which fails mechanically and leads to subduction initiation. Please refer to Table 1 for the rheological and thermal properties of all the materials used.

\subsection{Experimental Strategy}

We ran several dozen thermo-mechanical simulations of subduction-accretion to discern patterns of thermal maturity evolution in wedge sediments. Here, we present a total of 9 models that vary in their effective basal friction or their effective sedimentation rate. We nominate models with variable effective internal angles with capital letters and models with variable sedimentation rate with numeric subindices. Models $\mathbf{W}_{\mathbf{0}}, \mathbf{M}_{\mathbf{0}}, \mathbf{S}_{\mathbf{0}}$ have no sedimentation and effective internal angle values for the décollement of $\boldsymbol{\phi}_{b}=$ $2^{\circ}, 7^{\circ}$ and $12^{\circ}$, which we conceptualize loosely as weak (W), medium (M) and strong (S) décollements. The rest of the models shown here, $\mathbf{M}_{\mathbf{0 . 1}}-\mathbf{M}_{0.6}$, have a medium-strength décollement and variable effective sedimentation rate ranging from 0.1 to $0.6 \mathrm{~mm} / \mathrm{yr}$. Sedimentation occurs at the trench in all of the models presented in this study from sea to land. With these models, we evaluate the particle trajectory and Ro\% 
of accreting sediments as a function of décollement strength $\left(\mathbf{W}_{\mathbf{0}}, \mathbf{M}_{\mathbf{0}}, \mathbf{S}_{\mathbf{0}}\right)$ and sedimentation rate $\left(\mathbf{M}_{0.1}-\mathbf{M}_{0.6}\right)$.

All models lack surface processes during the first $\sim 2.5 \mathrm{My}$, and have sedimentation thereafter. Sediments used in the model have an angle of friction of $30^{\circ}$ and a strain-softened value of $15^{\circ}$ to account for weakening caused due to accumulated failure. Sedimentation rates are the effective sedimentation rate computed after the model run, and are thus not prescribed a priori. This choice ensures that the range of average sedimentation in all our models $(0-0.6 \mathrm{~mm} / \mathrm{yr})$ lies within observed sedimentation rates in our chosen natural equivalent, the Nankai accretionary wedge in the south-western subduction margin of Japan(Korup et al., 2014). Table 2 provides more details about the model run and prescribed sedimentary conditions.

\section{Results}

Subduction begins at $0.1 \mathrm{Myr}$ as the weak material between continental and oceanic plates fails (see

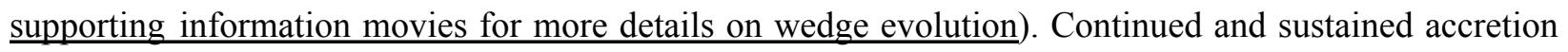
of sediments against the deforming continental crust forms the accretionary wedge from the interplate contact landwards. After $\sim 5 \mathrm{Myr}$, all models develop a distinct wedge in agreement with the critical taper theory(Davis et al., 1983). Taper angles increase by more than an order of magnitude as effective internal angles increase by $\sim 10^{\circ}$ (Table 2). Concretely, whereas models with a relatively weaker décollement, as $\mathrm{W}_{0}\left(\boldsymbol{\phi}_{b}=2^{\circ}\right)$, have taper slopes of $\sim 1.2^{\circ} \pm 0.4^{\circ}$, models with very strong décollement, as $\mathrm{S}_{0}\left(\boldsymbol{\phi}_{b}=12^{\circ}\right)$, have slopes as steep as $\sim 18.8 \pm 3.1^{\circ}$. Contrarily, increasing trench sedimentation rate leads to lower wedge-taper angles, albeit with a larger standard deviation (Table 2). Steeper surface slopes with increased décollement strengths and gentler slopes with increased sedimentation are well-known effects that have been confirmed by previous numerical(Mannu et al., 2016; Wang and He, 1999) and analytical(Malavieille and Trullenque, 2009; Storti and Mcclay, 1995) models. 
Models without trench sedimentation grow solely by accretion of incoming seafloor sediments, with frequent nucleation of frontal thrusts. Models with weaker décollements develop thrusts that are the lengthier and remain active for shorter periods of time. This is clear when comparing, for models with increasingly strong decollements $\left(\mathrm{W}_{0}, \mathrm{M}_{0}, \mathrm{~S}_{0}\right)$, the average distance between first and second frontal thrust and their average time of nucleation; these are $4.0 \pm 2.2 \mathrm{~km}, 3.8 \pm 1.6 \mathrm{~km}$ and $3.4 \pm 2.2 \mathrm{~km}$, and $0.20 \mathrm{Myr}$, 0.25 Myr and 0.34 Myr, respectively. Increasing sedimentation rate also leads to an increase in thrust sheet length. Compared to the model without sedimentation, models with higher sedimentation rate have lengthier thrust sheets which remain active for longer periods of time (Table 2).

All décollement-strength models without sedimentation $\left(\mathrm{W}_{0}, \mathrm{M}_{0}\right.$, and $\left.\mathrm{S}_{0}\right)$ exhibit temperature gradient that corresponds well with the temperature profile observed in the boreholes at IODP Site C0002 in the Kumano forearc basin, on top of the Nankai accretionary wedge (Fig. S2).

\subsection{Thermal maturity of the wedge}

Sediments are more thermally mature in wedges that have a higher sedimentation rate or décollement strength. For example, the mean $\mathrm{R}_{0} \%$ of simulations for wedges with high sedimentation $\left(\mathrm{M}_{0.6}\right)$ is 0.21 (43\%) higher than in those without sedimentation $\left(\mathrm{M}_{0}\right)$ (Table 2). Similarly, simulations of wedges with the strongest décollement have the highest mean $\mathrm{R}_{0} \%$ of all the simulations presented in this study.

Thermal maturity values increase with depth and with landward distance, from the trench to the forearc high (Fig. 1). As a result, sediments at the core of the wedge consistently reach the highest maturity. Both the absolute value of $\mathrm{R}_{0} \%$ and the rate at which thermal maturity values increase landward from the trench are large for wedges with high sedimentation rate or high décollement strength. Comparing the values of $\mathrm{R}_{0} \%$ (Fig. 1E) along an arbitrary horizon in several models (Fig. 1A-1D) 
emphasizes this result; the model with the highest sedimentation attains the maximum $\mathrm{R}_{0} \%$ of 1.45 , whereas the rate of landward increase in thermal conductivity is highest for the wedge with strongest décollement (Fig. 1). All models show a decrease in thermal maturity landward of the forearc high, commonly of $0.2 \mathrm{R}_{0} \%$. Other interesting observations that we explore below are the increased thermal maturity occurring in the vicinity of thrusts (Fig. 1C), and the reversal in sediment maturity that takes place in faults active over longer times (Fig. 1B, 1D).

\subsection{Sediment trajectory inside the wedge}

Sediments follow high-maturity paths in larger proportions in wedges with a higher décollement strength or sedimentation rate. We demonstrate this effect by computing the average depth of the trajectories normalized by the thickness of the wedge in a parameter $Y_{n}$ that ranges from 0 to 1 and has a smaller value the closer the trajectory of sediments is to the décollement (Fig. 2). Models with weak and medium strength décollements ( $W_{0}$ and $M_{0}$ in Fig. 2) have $Y_{n}<0.5$ for slightly above half of the trajectories of its sediments (58\% and 52\% respectively), indicating depths closer to the décollement. Models with high strength décollement or sedimentation rates $\left(S_{0}\right.$ and $M_{0.6}$ in Fig. 2$)$ have four fifths and two thirds of all sediments (79\% and 64\% respectively) following depth-paths closer to the décollement than to the surface. These models also include large contiguous zones, such as $\mathrm{B}_{\mathrm{S} 0}-\mathrm{D}_{\mathrm{S} 0}$ and $\mathrm{D}_{\mathrm{M} 0.6}-\mathrm{F}_{\mathrm{M} 0.6}$, where all sediment trajectories have $Y_{n}<0.25$ (Fig 2). Since the depth of the sedimentary trajectories correlates with $\log \left(\mathrm{R}_{0} \%\right)$, sediments in wedges with lower $\mathrm{Y}_{\mathrm{n}}$ values have high thermal maturity (Fig 3). Furthermore, Fig.3, shows that models with higher sedimentation rate and décollement strength tend to have higher $\mathrm{R}_{0} \%$ at similar $\mathrm{Y}_{\mathrm{n}}$.

\subsection{Patterns of trajectory and thermal maturity in incoming sediments}

We create a contour map of the thermal maturity of sediments at 7.5 Myr of model run, mapped to their spatial position $5 \mathrm{Myr}$ earlier (at 2.5 My of model run) (Fig. 4) in order to analyse the spatial 
correlation between sediment position (depth and distance) from the trench and thermal maturity. We define a thermal maturity boundary where $\mathrm{R}_{0} \%=1.5$ (line $\mathrm{P}_{1.5}$ in Fig 4) and differentiate sediments below and above it, which have a relatively higher and lower maturity $\left(\mathrm{R}_{0} \%>1.5\right.$ and $\mathrm{R}_{0} \%<1.5$ respectively).

Our defined thermal maturity boundary has sharp changes with distance from the trench that relate to changes in sediment trajectory (Fig. 4). The thermal maturity boundary is variable along the horizontal length of the wedge, and has a periodicity increasing in distance with higher décollement strength and sedimentation rate (Fig. 4; Table 2). Whereas the thermal maturity boundary has a periodicity at horizontal distances of $\sim 16 \mathrm{~km}$ and $22 \mathrm{~km}$ in weak- and medium-strength décollement models $\left(\mathrm{W}_{0}\right.$ and $\mathrm{M}_{0}$ ), the periodicity decreases to one third, to $\sim 50 \mathrm{~km}$ and $57 \mathrm{~km}$, when décollement strength or sedimentation rate are high $\left(\mathrm{S}_{0}\right.$ and $\left.\mathrm{M}_{0.6}\right)$, respectively. The increase in periodicity due to sedimentation can also be observed in models $\mathrm{M}_{0}-\mathrm{M}_{0.6}$ presented in Table 2.

Increasing sedimentation rates or décollement strength leads sediments at shallow positions onto high-maturity routes closer to décollement (Fig. 4). Whereas in wedges with weak decollements $\left(\mathrm{W}_{0}\right)$ only $1 \%$ of the shallowest $250 \mathrm{~m}$ of incoming sediments reach $\mathrm{R}_{0} \%>0.5$, more than one third (37\%) of sediments reach this value in wedges with strong décollements $\left(S_{0}\right)$. The effects of décollement strength in the thermal maturity of sediments can be quantified as well at deeper levels, with one fifth and two thirds of sediments surpassing values of $\mathrm{R}_{0} \%=1.5$ at $750 \mathrm{~m}$ depth ( $21 \%$ and $71 \%$ respectively) in weak and strong-decollement wedges, respectively. Increasing the sedimentation rate has similar effects. In wedges from models without sedimentation, only $4 \%$ of the top $250 \mathrm{~m}$ of sediments yield Ro $\%>1.5$, while up to $40 \%$ of them surpass the thermal maturity boundary in the models with a sedimentation rate of $0.6 \mathrm{~mm} / \mathrm{yr}$ $\left(\mathrm{M}_{0.6}\right)$. In sum, the proportion of sediments in the top $250 \mathrm{~m}$ and $750 \mathrm{~m}$ of the wedge that reach $\mathrm{R}_{0} \%>1.5$ steadily increases with both sedimentation rate and décollement strength (Table 2). 


\section{Discussion}

Our models achieve realistic thermal maturity distributions thanks to unique computational advantages over models in previous studies(Mannu et al., 2017, 2016; Miyakawa et al., 2019), despite incurring in several relevant assumptions. Models are simplified by assuming no elasticity, and by using a simple and uniform rheology, and either have insufficient resolution or lack empirical relations to simulate the compaction of sediments and processes of multiscale fluid flow. Although these assumptions hinder a wholesale comparison between our simulations and natural examples of accretionary wedges, we are confident of the thermal maturity patterns of our models, as they correlate with the patterns of P-wave velocity(Dewing and Sanei, 2009) (Fig S4). This correlation between the patterns of thermal maturity and P-wave velocity has been shown for Nankai(Górszczyk et al., 2019; Nakanishi et al., 2018) and Hikurangi(Arai et al., 2020) margins. Models compute realistic thermal maturity distributions thanks to several key improvements. Firstly, our models calculate temperature gradients that evolve at long time intervals, and thus closely replicate that of accretionary wedges in nature (Fig. S2). This enables the simulation of realistic temperature profiles based on thermal conductivity values derived empirically from real accretionary wedges, as in our case, the Nankai margin(Sugihara et al., 2014) Secondly, our models implement realistic surface processes that vary fully in space and time. Thirdly, our simulations account for the effects that thermal and isostatic feedback from the oceanic lithosphere have on the evolution of the wedge, by simulating plate subduction at large scale rather than just the accretionary wedge(Miyakawa et al., 2019). Finally and importantly, our method calculates the vitrinite reflectance of sediments on each marker of the mesh. This relevantly expands the numerical precision of previous efforts(Mannu et al., 2017, 2016), as it allows tracking the evolution of thermal maturity in sediments more efficiently. This capacity to accurately estimate thermal maturity in each marker informs the research questions of this study and allows inferences beyond those of depth-dependent thermal maturity distributions. 
The thermal maturity of the wedge increases landward, as signaled by the landward increase in $\mathrm{R}_{0} \%$ (Fig. 1). This has been observed both in natural accretionary wedges(Yamamoto et al., 2017) and other numerical models of accretion(Miyakawa et al., 2019), and results from the long-term deformation of older accreted sediments and the backstop-forced exhumation in the wedge. Our models show that the rate of landward rise in thermal maturity is faster for thicker wedges (Fig 1). This is the case for wedges with high basal strength and larger sedimentation input, for sediments in thicker wedges deform more prominently than those in their thinner counterparts. Simulations also show that sediments reach deeper levels in thicker wedges, and that this increases the overall thermal maturity of the wedge. Also, increased exhumation rates and steeper thermal maturity gradients take place in the wedge interior, as the continental backstop deflect sediment trajectories upwards during accretion (Fig. 2). As a result, backstop-forced exhumed material is, on an average, thermally more mature.

Our models expose two relevant cases where the increase of thermal maturity with depth or that landward are relevantly altered: on-fault increase and fault-block inversion. Our models attest the steep increase in thermal maturity of sediments at fault sites (Fig. 1C). This is well documented in nature, as for boreholes C0004 and C0007(Sakaguchi et al., 2011). However, on-fault increases in thermal maturity are comparatively smaller in our simulations and lack the marked increase in Ro\% observed at fault sites in nature. This is primarily due to our models developing wider fault zones than their natural equivalents, and the subsequent acceleration in the thermal diffusion occurring in simulated thrusts. During fault-block inversions, the positive gradient of thermal maturity with depth is inverted by thrusting of relatively mature sediments over less mature sediments(Underwood et al., 1992), as shown in Fig. 3B. This is known from natural observations, as along the Fukase Fault in Shimanto accretionary wedge(Ohmori et 
al., 1997) and underneath the forearc basin in Nankai accretionary wedge(Fukuchi et al., 2017), and previous modeling efforts(Miyakawa et al., 2019).

Collation of the above implies that the thermal maturity of accretionary wedges results from the general increase of thermal maturity (i) with depth and (ii) landward, as well as from its (iii) modification by thrust faults. Our models suggest thermal maturity inversions by thrusting, which are commonplace in accretionary contexts, are the primary cause of thermal maturity differentiation among wedges with initially similar geothermal gradient. In other words, the strong differentiation in the trajectory of sediments led by thrusting has a larger influence over thermal maturity than burial depth or in-wedge location. This novel inference has probably remained concealed thus far due to the large number of parameters that condition thrust development, frequency, length and thermal state. Influencing parameters include sedimentation, erosion, basal friction and relief, pore pressure and fluid state, wedge length and thickness, taper angle, and many others(Dominguez et al., 2000; Konstantinovskaia, 2005; Mannu et al., 2016; Simpson, 2010; Tobin and Saffer, 2009). It is nevertheless important to note that the frequency of faults in a wedge can be impacted by many other factors, including hinterland sedimentation(Simpson, 2010; Storti and Mcclay, 1995), erosion(Konstantinovskaia, 2005; Willett, 1999), and seafloor topography(Dominguez et al., 2000). Below, we discuss how thrusts not only alter the thermal evolution of accreting sediments but are in fact the primary control on their thermal maturity.

Thermal maturity correlates with sediment depth weakly near faults and more strongly away from them. The distance of sediment from frontal thrust dictates the trajectory of sediment grains, and as a result, the pressure-temperature conditions to which they are exposed. In this study, we have considered solely how décollement strength and the rate of trench sedimentation vary the frequency, architecture, and overall behavior of thrusts, and the frontal thrust, as the wedge evolves. Our results show the need to consider all factors influencing fault frequency when inferring the geothermal history of contractional terrains by means of thermal maturity. Fortunately, this predictive exercise should be relatively 
straightforward, for the impact of these external factors on the fault structure of wedges has been established(Fillon et al., 2012; Mannu et al., 2017, 2016; Mugnier et al., 1997; Simpson, 2010; Storti and Mcclay, 1995), and the impact of each of these factors can be accounted for when assessing the trajectory of sediments and the distribution of thermal maturity in accretionary wedges.

Sediment mixing in subduction wedges is primarily controlled by thrusting. Previous studies have reached seemingly contradicting outcomes when using numerical(Miyakawa et al., 2019; Wenk and Huhn, 2013; Willett et al., 1993) and analogue(Konstantinovskaia, 2005; Mulugeta and Koyi, 1992) approaches to analyze sediment trajectories as a function of changes in erosion, sedimentation or décollement strength. While some studies showed that the rate and extent of a transition by which sediment trajectories change from generally horizontal to increasingly vertical during accretion change consistently with the initial depth of incoming sediments(Mulugeta and Koyi, 1992; Willett, 1992), others predicted different crossover paths for sediments accreting over a range of décollement strengths(Konstantinovskaia, 2005). Our models show that both are valid results, and that changes in trajectory patterns leading to path crossovers are controlled by the horizontal distance of sediments from the frontal thrust. Starting at a threshold distance from the trench, sediments at different depths follow laminar paths along different trajectories within the wedge. Laminar-type trajectories can be reproduced in a broad range of simulations and are particularly common in models with low sedimentation and décollement strengths. However, the depth dependence of sedimentary paths varies periodically as a function of distance from the trench of specific sedimentary packages (Fig. 2, 5). This effect, which is particularly marked in the neighborhood of the frontal thrust, explains the crossover paths for incoming sedimentary packages at similar depths and different horizontal locations, as shown by Konstantinovskaia et al. 2005. Therefore, thrust faults in the wedge act as the primary agent controlling whether sediments sustain depth-controlled laminar flow or mix. 
The thermal maturity that incoming sediments reach varies periodically as a function of thrust frequency. Although previous research considered non-laminar sediment trajectories as chaotic(Mary et al., 2013), and the broad variety of trajectories shown in our models seem to agree with this (Fig 2), patterns emerge when we correlate the lateral and vertical position of incoming sediments with their eventual thermal maturity. Changes in the depth of the thermal maturity boundary are less frequent and have larger amplitudes with increased décollement strength, and especially, increased sedimentation rates (Fig. 4). The periodicity in the thermal maturity boundary marks the periodic oscillation of the predominant trajectory followed by incoming sediments, i.e. between accretion (low thermal maturity path) and underthrusting (high-thermal maturity path). As a result, it should also strongly correlate with the periodicity observed in the evolution of forearc topography(Menant et al., 2020). This is expected, given that thrusts are active over longer mean times, and they thus channel material toward the décollement more efficiently, in wedges with stronger décollement or increased sedimentation. While sediments at internal and higher structural positions of the wedge are translated towards the surface and have a lower thermal maturity, sediments at external and lower structural positions are translated towards the décollement and have a relatively higher maturity. This is a relevant observation, for it typifies the causality of particular sediment grains following a high or low maturity path, a long-standing unanswered question(Miyakawa et al., 2019). We corroborate this observation by analyzing the terminal thermal maturity of sediments across a frontal thrust active at a younger age. For example, by showing the thermal maturity of sediments at $\sim 7.5 \mathrm{Myr}$ across a thrust active at $\sim 4 \mathrm{Myr}$, as in Fig. 6. Whereas this occurs for all thrusts in the wedge, the frontal thrust is particularly pronounced in partitioning sediments into the high and low maturity paths.

Geothermal information stored in the incoming sediments can only be retrieved if sediments are at appropriate locations with respect to emergent thrusts. We illustrate this using two runs of the same model and tracking an artificial thermal anomaly imposed on incoming sediments at two different locations (Fig. 6). This hypothetical thermal anomaly can be conceptualized as any alteration of the 
thermal maturity profile of incoming sediments, as for example, elevated heat flows by an antecedent magmatic intrusion. While the change in $\mathrm{R}_{0} \%$ associated with the short-lived thermal anomaly results in abnormally high values of thermal maturity in both sediment packages, it can only be retrieved for the end-model run of sediments located further from the trench (those in the right panel, Fig. 6b). Contrarily, the end-model run of sediments closer to the trench (those in the left panel, Fig. 6a) shows no signs of discontinuity in the thermal maturity distribution of the wedge. This is because we deliberately placed the thermal anomaly at sites that evolve at two structural locations during the model run, i.e. above and below a yet-undeveloped frontal thrust (Fig. 6). The sediment sector affected by the thermal anomaly closer to trench is overthrusted by the frontal thrust and remains in a footwall location thereafter (Fig. 6a), whereas the homologous sedimentary package further away from the trench is accreted by the frontal thrust and remains in a hanging-wall location (Fig. 6b). Thus, the preservation of the record of an antecedent thermal anomaly is only possible in the former case. We further note that, in our simulations, the entire vertical column of sediments records the thermal anomaly, while in nature the anomaly may affect only sediments at the deeper locations of the sedimentary pile, which are in turn the sediments that most likely to follow a high-maturity path. We thus regard the possibility of retrieving such antecedent geothermal information as minimal.

The main implications of this contribution emerge from its predictive power. Our approach can predict to a first order the thermal maturity of sediments in accretionary contexts with known structuration. A more accurate quantification of the thermal evolution and thermal state of accreted sediments reduces the uncertainties attached to the location of temperature-led transformations of organic material into hydrocarbons, in subduction margins and other accretionary contexts. Such increased accuracy in the distribution of thermally mature sediments may also be applied for improved assessments of the evolution in time of any other geothermal process, including seismic slip, magmatic and metamorphic extent, porosity, compaction and diagenesis of sediments, and the reconstruction of convergent margins in 
general(Bostick and Pawlewicz, 1984; Ferreiro Mählmann and Le Bayon, 2016; Rabinowitz et al., 2020; Sakaguchi et al., 2011; Totten and Blatt, 1993; Underwood et al., 1992)

\section{Conclusion}

This study demonstrates how contractional faults alter the paths of sediments as they accrete, and how this fundamentally controls the distribution of the thermal maturity of sediments in accretionary wedges, and emphasizes the role that sedimentation rate and interplate contact strength have in such distribution. The increased resolution of our approach leads to findings that have relevant implications. For example, the geothermal history that can be retrieved from the thermal maturity of sediments in drills, i.e. at the shallow wedge, provides, at best, an incomplete record that is skewed towards the thermal evolution of sediments near the trench. Coevally, relevant sectors of sediments located further seaward, when not subducted, follow high-maturity paths that overprint their antecedent thermal history. Finally, this study also provides a first-order predictive indicator for thermal maturity of sediments based on the distribution of faults.

\section{Acknowledgement}

The work was supported by a INSPIRE Faculty Fellowship by DST, India and Earthquake Research Institute (ERI), The University of Tokyo.

\section{References}

1. Arai, R., Kodaira, S., Henrys, S., Bangs, N., Obana, K., Fujie, G., Miura, S., Barker, D., Bassett, D., Bell, R., Mochizuki, K., Kellett, R., Stucker, V., Fry, B., NZ3D Team, 2020.

Three-dimensional P wave velocity structure of the northern hikurangi margin from the NZ3D 
experiment: Evidence for fault-bound anisotropy. J. Geophys. Res. [Solid Earth] 125. https://doi.org/10.1029/2020jb020433

2. Bostick, N.H., Pawlewicz, M.J., 1984. Paleotemperatures based on vitrinite reflectance of shales and limestone in igneous dike aureoles in the Upper Cretaceous Pierre shale, Walsenburg, Colorado.

3. Burg, J.-P., Gerya, T.V., 2005. The role of viscous heating in Barrovian metamorphism of collisional orogens: thermomechanical models and application to the Lepontine Dome in the Central Alps. J. Metamorph. Geol. 23, 75-95. https://doi.org/10.1111/j.1525-1314.2005.00563.x

4. Burnham, A.K., Sweeney, J.J., 1989. A chemical kinetic model of vitrinite maturation and reflectance. Geochim. Cosmochim. Acta 53, 2649-2657. https://doi.org/10.1016/0016-7037(89)90136-1

5. Byrne, T., Fisher, D., 1990. Evidence for a weak and overpressured décollement beneath sediment-dominated accretionary prisms. Journal of Geophysical Research. https://doi.org/10.1029/jb095ib06p09081

6. Davis, D., Suppe, J., Dahlen, F.A., 1983. Mechanics of fold-and- thrust belts and accretionary wedges. Journal of Geophysical Research. https://doi.org/10.1029/JB088iB02p01153

7. Dewing, K., Sanei, H., 2009. Analysis of large thermal maturity datasets: Examples from the Canadian Arctic Islands. Int. J. Coal Geol. 77, 436-448. https://doi.org/10.1016/j.coal.2008.04.009

8. Dominguez, S., Malavieille, J., Lallemand, S.E., 2000. Deformation of accretionary wedges in response to seamount subduction: Insights from sandbox experiments. Tectonics 19, 182-196. https://doi.org/10.1029/1999tc900055

9. Ferreiro Mählmann, R., Le Bayon, R., 2016. Vitrinite and vitrinite like solid bitumen reflectance in thermal maturity studies: Correlations from diagenesis to incipient metamorphism in different geodynamic settings. Int. J. Coal Geol. 157, 52-73. https://doi.org/10.1016/j.coal.2015.12.008 
10. Fillon, C., Huismans, R.S., van der Beek, P., 2012. Syntectonic sedimentation effects on the growth of fold-and-thrust belts. Geology 41, 83-86. https://doi.org/10.1130/G33531.1

11. Fukuchi, R., Yamaguchi, A., Yamamoto, Y., Ashi, J., 2017. Paleothermal structure of the N ankai inner accretionary wedge estimated from vitrinite reflectance of cuttings. Geochem. Geophys.

Geosyst. 18, 3185-3196. https://doi.org/10.1002/2017gc006928

12. Gerya, T., 2019. Introduction to Numerical Geodynamic Modelling. Cambridge University Press.

13. Gerya, T.V., Yuen, D.A., 2003. Characteristics-based marker-in-cell method with conservative finite-differences schemes for modeling geological flows with strongly variable transport properties. Phys. Earth Planet. Inter. 140, 293-318. https://doi.org/10.1016/j.pepi.2003.09.006

14. Górszczyk, A., Operto, S., Schenini, L., Yamada, Y., 2019. Crustal-scale depth imaging via joint full-waveform inversion of ocean-bottom seismometer data and pre-stack depth migration of multichannel seismic data: a case study from the eastern Nankai Trough. Solid Earth 10, $765-784$.

15. Konstantinovskaia, E., 2005. Erosion and exhumation in accretionary orogens: Experimental and geological approaches. Geochem. Geophys. Geosyst.

16. Korup, O., Hayakawa, Y., Codilean, A.T., Matsushi, Y., Saito, H., Oguchi, T., Matsuzaki, H., 2014. Japan's sediment flux to the Pacific Ocean revisited. Earth-Sci. Rev. 135, 1-16. https://doi.org/10.1016/j.earscirev.2014.03.004

17. Luján, M., Rossetti, F., Storti, F., Ranalli, G., A. Socquet, 2010. Flow trajectories in analogue viscous orogenic wedges: Insights on natural orogens. Tectonophysics 484, 119-126. https://doi.org/10.1016/j.tecto.2009.09.009

18. Malavieille, J., Trullenque, G., 2009. Consequences of continental subduction on forearc basin and accretionary wedge deformation in SE Taiwan: Insights from analogue modeling. Tectonophysics 466, 377-394. https://doi.org/10.1016/j.tecto.2007.11.016

19. Mannu, U., Ueda, K., Willett, S.D., Gerya, T.V., Strasser, M., 2017. Stratigraphic signatures of 
forearc basin formation mechanisms. Geochem. Geophys. Geosyst. 18, 2388-2410.

20. Mannu, U., Ueda, K., Willett, S.D., Gerya, T.V., Strasser, M., 2016. Impact of sedimentation on evolution of accretionary wedges: Insights from high-resolution thermomechanical modeling. Tectonics. https://doi.org/10.1002/2016tc004239

21. Mary, B.C.L., Maillot, B., Leroy, Y.M., 2013. Deterministic chaos in frictional wedges revealed by convergence analysis. International Journal for Numerical and Analytical Methods in Geomechanics. https://doi.org/10.1002/nag.2177

22. Menant, A., Angiboust, S., Gerya, T., Lacassin, R., Simoes, M., Grandin, R., 2020. Transient stripping of subducting slabs controls periodic forearc uplift. Nat. Commun. 11, 1823. https://doi.org/10.1038/s41467-020-15580-7

23. Miyakawa, A., Kinoshita, M., Hamada, Y., Otsubo, M., 2019. Thermal maturity structures in an accretionary wedge by a numerical simulation. Progress in Earth and Planetary Science 6, 8. https://doi.org/10.1186/s40645-018-0252-z

24. Mugnier, J.L., Baby, P., Colletta, B., Vinour, P., Bale, P., Leturmy, P., 1997. Thrust geometry controlled by erosion and sedimentation: A view from analogue models. Geology 25, 427-430. https://doi.org/10.1130/0091-7613(1997)025<0427:TGCBEA>2.3.CO

25. Mulugeta, G., Koyi, H., 1992. Episodic accretion and strain partitioning in a model sand wedge. Tectonophysics 202, 319-333. https://doi.org/10.1016/0040-1951(92)90117-O

26. Nakanishi, A., Takahashi, N., Yamamoto, Y., Takahashi, T., Citak, S.O., Nakamura, T., Obana, K., Kodaira, S., Kaneda, Y., Byrne, T., Others, 2018. Three-dimensional plate geometry and P-wave velocity models of the subduction zone in SW Japan: Implications for seismogenesis. Geology and Tectonics of Subduction Zones: A Tribute to Gaku Kimura: Geological Society of America Special Paper 534, 69-86.

27. Ohmori, K., Taira, A., Tokuyama, H., Sakaguchi, A., Okamura, M., Aihara, A., 1997. Paleothermal structure of the Shimanto accretionary prism, Shikoku, Japan: Role of an 
out-of-sequence thrust. Geology 25, 327-330.

https://doi.org/10.1130/0091-7613(1997)025<0327:PSOTSA>2.3.CO;2

28. Quigley, T.M., Mackenzie, A.S., 1988. The temperatures of oil and gas formation in the sub-surface. Nature 333, 549-552.

29. Rabinowitz, H.S., Savage, H.M., Polissar, P.J., Rowe, C.D., Kirkpatrick, J.D., 2020. Earthquake slip surfaces identified by biomarker thermal maturity within the 2011 Tohoku-Oki earthquake fault zone. Nat. Commun. 11, 533. https://doi.org/10.1038/s41467-020-14447-1

30. Ranalli, G., 1995. Rheology of the Earth. Springer Science \& Business Media.

31. Sakaguchi, A., Chester, F., Curewitz, D., Fabbri, O., Goldsby, D., Kimura, G., Li, C.-F., Masaki, Y., Screaton, E.J., Tsutsumi, A., Ujiie, K., Yamaguchi, A., 2011. Seismic slip propagation to the updip end of plate boundary subduction interface faults: Vitrinite reflectance geothermometry on Integrated Ocean Drilling Program NanTro SEIZE cores. Geology. https://doi.org/10.1130/g31642.1

32. Schmoker, J.W., Gautier, D.L., 1988. Sandstone porosity as a function of thermal maturity. Geology 16, 1007-1010. https://doi.org/10.1130/0091-7613(1988)016<1007:SPAAFO>2.3.CO;2

33. Simpson, G.D.H., 2010. Formation of accretionary prisms influenced by sediment subduction and supplied by sediments from adjacent continents. Geology 38, 131-134. https://doi.org/10.1130/G30461.1

34. Storti, F., Mcclay, K., 1995. Influence of syntectonic sedimentation on thrust wedges in analogue models. https://doi.org/10.1130/0091-7613(1995)023<0999

35. Sugihara, T., Kinoshita, M., Araki, E., Kimura, T., Kyo, M., Namba, Y., Kido, Y., Sanada, Y., Thu, M.K., 2014. Re-evaluation of temperature at the updip limit of locked portion of Nankai megasplay inferred from IODP Site C0002 temperature observatory. Earth, Planets and Space. https://doi.org/10.1186/1880-5981-66-107

36. Suzuki, N., Matsubayashi, H., Waples, D.W., 1993. A Simpler Kinetic Model of Vitrinite 
Reflectance. AAPG Bull. 77, 1502-1508.

https://doi.org/10.1306/BDFF8ECA-1718-11D7-8645000102C1865D

37. Tissot, B.P., Pelet, R., Ungerer, P.H., 1987. Thermal History of Sedimentary Basins, Maturation Indices, and Kinetics of Oil and Gas Generation. AAPG Bull. 71, 1445-1466.

https://doi.org/10.1306/703C80E7-1707-11D7-8645000102C1865D

38. Tissot, B.P., Welte, D.H., 2013. Petroleum Formation and Occurrence. Springer Science \& Business Media.

39. Tobin, H., Hirose, T., Saffer, D., Toczko, S., Maeda, L., Kubo, Y., Boston, B., Broderick, A., Brown, K., Crespo-Blanc, A., Even, E., Fuchida, S., Fukuchi, R., Hammerschmidt, S., Henry, P., Josh, M., Jurado, M.J., Kitajima, H., Kitamura, M., Maia, A., Otsubo, M., Sample, J., Schleicher, A., Sone, H., Song, C., Valdez, R., Yamamoto, Y., Yang, K., Sanada, Y., Kido, Y., Hamada, Y., 2015. Site C0002. Proceedings of the IODP. https://doi.org/10.2204/iodp.proc.348.103.2015

40. Tobin, H.J., Saffer, D.M., 2009. Elevated fluid pressure and extreme mechanical weakness of a plate boundary thrust, Nankai Trough subduction zone. Geology 37, 679-682. https://doi.org/10.1130/G25752A.1

41. Totten, M.W., Blatt, H., 1993. Alterations in the non-clay-mineral fraction of pelitic rocks across the diagenetic to low-grade metamorphic transition, Ouachita Mountains, Oklahoma and Arkansas. J. Sediment. Res. 63, 899-908. https://doi.org/10.1306/D4267C3F-2B26-11D7-8648000102C1865D

42. Underwood, M.B., Laughland, M.M., Byrne, T., Hibbard, J.P., DiTullio, L., 1992. Thermal evolution of the Tertiary Shimanto Belt, Muroto Peninsula, Shikoku, Japan. The Island Arc. https://doi.org/10.1111/j.1440-1738.1992.tb00064.x

43. Wang, K., He, J., 1999. Mechanics of low-stress forearcs: Nankai and Cascadia. J. Geophys. Res. [Solid Earth] 104, 15191-15205.

44. Waples, D.W., 1981. Organic Geochemistry for Exploration Geologists. Springer Netherlands. 
45. Wenk, L., Huhn, K., 2013. The influence of an embedded viscoelastic-plastic layer on kinematics and mass transport pattern within accretionary wedges. Tectonophysics 608, 653-666. https://doi.org/10.1016/j.tecto.2013.08.015

46. Willett, S., 1992. Dynamic and kinematic growth and change of a Coulomb wedge. McClay, K. R. 19-31.

47. Willett, S., Beaumont, C., Fullsack, P., 1993. Mechanical model for the tectonics of doubly vergent compressional orogens. Geology. https://doi.org/10.1130/0091-7613(1993)021<0371:MMFTTO>2.3.CO

48. Willett, S.D., 1999. Orogeny and orography: The effects of erosion on the structure of mountain belts. J. Geophys. Res. 104, 28957. https://doi.org/10.1029/1999JB900248

49. Yamamoto, Y., Hamada, Y., Kamiya, N., Ojima, T., Chiyonobu, S., Saito, S., 2017. Geothermal structure of the Miura-Boso plate subduction margin, central Japan. Tectonophysics 710-711, 81-87. https://doi.org/10.1016/j.tecto.2016.11.004 


\section{List of Tables}

Table 1: Properties for the different material used for the model runs

\begin{tabular}{|c|c|c|c|c|c|c|c|}
\hline Rock Type & $\begin{array}{l}\text { Density } \\
\left(\mathrm{kg} / \mathrm{m}^{3}\right)\end{array}$ & $\begin{array}{l}\text { Cohesion } \\
\text { (MPa) }\end{array}$ & $\begin{array}{l}\text { Coefficient } \\
\text { of friction }(u)\end{array}$ & \begin{tabular}{|l|} 
Thermal \\
Conductivity \\
$(\mathrm{W} /(\mathrm{m} \mathrm{K}))$ \\
\end{tabular} & Flow law & $\begin{array}{l}\mathbf{E} \\
(\mathrm{kJ} / \mathrm{mol})\end{array}$ & n \\
\hline Water & 1000 & 0 & 0 & 20 & & 0 & 0 \\
\hline \begin{tabular}{|l} 
Air \\
(Sticky-air)
\end{tabular} & 0 & 0 & 0 & 20 & & 0 & 0 \\
\hline Décollement & 2600 & 0.001 & \begin{tabular}{|l|l}
0.03 \\
0.08 \\
\end{tabular} & $\begin{array}{l}(1.5+807 /(T+77))^{*} \\
\left(1-\exp \left(-Z^{2} / 1.3 \mathrm{e} 7\right)\right)\end{array}$ & Wet quartzite & 154 & 2.3 \\
\hline Sediments1 & 2600 & $0.5 / 0.05^{*}$ & $4.64 / 0.2^{*}$ & $\begin{array}{l}(0.96+807 /(\mathrm{T}+77))^{*} \\
\left(1-\exp \left(-\mathrm{Z}^{2} / 1.3 \mathrm{e} 7\right)\right)\end{array}$ & Wet quartzite & 154 & 2.3 \\
\hline Sediments2 & 2600 & $0.5 / 0.05^{*}$ & $4.64 / 0.2^{*}$ & $\begin{array}{l}(0.96+807 /(\mathrm{T}+77))^{*} \\
\left(1-\exp \left(-\mathrm{Z}^{2} / 1.3 \mathrm{e} 7\right)\right)\end{array}$ & Wet quartzite & 154 & 2.3 \\
\hline $\begin{array}{l}\text { Upper Continental } \\
\text { Crust }\end{array}$ & 2700 & 1 & 0.6 & $0.64+807 /(\mathrm{T}+77)$ & Wet quartzite & 300 & 2.3 \\
\hline $\begin{array}{l}\text { Lower Continental } \\
\text { Crust }\end{array}$ & 2800 & 1 & 0.6 & $0.64+807 /(\mathrm{T}+77)$ & Wet quartzite & 300 & 3.2 \\
\hline $\begin{array}{l}\text { Upper Oceanic } \\
\text { Crust }\end{array}$ & 3000 & 1 & 0.6 & $1.18+474 /(\mathrm{T}+77)$ & $\begin{array}{l}\text { Plagioclase } \\
\text { An75 }\end{array}$ & 300 & 2.3 \\
\hline $\begin{array}{l}\text { Lower Oceanic } \\
\text { Crust }\end{array}$ & 3000 & 1 & 0.6 & $1.18+474 /(T+77)$ & $\begin{array}{l}\text { Plagioclase } \\
\text { An75 }\end{array}$ & 300 & 3.2 \\
\hline Mantle Lithosphere & 3300 & 1 & 0.6 & $0.73+1293 /(\mathrm{T}+77)$ & Dry olivine & 532 & 3.5 \\
\hline Asthenosphere & 3300 & 1 & 0.6 & $0.73+1293 /(\mathrm{T}+77)$ & Dry olivine & 532 & 3.5 \\
\hline
\end{tabular}


Table 2: Model runs.

\begin{tabular}{|c|c|c|c|c|c|c|c|c|c|c|c|}
\hline Models & $\varphi_{\mathrm{b}}$ & $\varphi / \varphi_{\mathrm{ss}}$ & $S R$ & $L$ & $\alpha$ & $D$ & $T$ & $<R_{o} \%>$ & $\%_{0.75}$ & $\%_{0.25}$ & $\lambda(\mathrm{km})$ \\
\hline$V_{0}$ & $2^{\circ}$ & $30^{\circ} / 15^{\circ}$ & None & $74.3 \pm 5.7$ & $1.2 \pm 0.4^{\circ}$ & $4.0 \pm 2.2$ & 0.20 & 0.39 & 20.9 & 1.2 & \\
\hline$M_{0}$ & $7^{\circ}$ & $30^{\circ} / 15^{\circ}$ & None & $58.4 \pm 5.4$ & $4.5 \pm 1^{\circ}$ & $3.8 \pm 1.6$ & 0.25 & 0.49 & 31.9 & 4.1 & \\
\hline$M_{1}$ & $7^{\circ}$ & $30^{\circ} / 15^{\circ}$ & 0.1 & $63.4 \pm 5.9$ & $4.4 \pm 1.0^{\circ}$ & $6.4 \pm 2.2$ & 0.22 & 0.58 & 31.8 & 13.2 & $22.1 \pm 3.6$ \\
\hline $\mathbf{M}_{2}$ & $7^{\circ}$ & $30^{\circ} / 15^{\circ}$ & 0.2 & $66.0 \pm 7.5$ & $3.2 \pm 0.8^{\circ}$ & $6.7 \pm 2.5$ & 0.30 & 0.54 & 46.8 & 12.6 & $24.5 \pm 7.8$ \\
\hline $\mathbf{M}_{3}$ & $7^{\circ}$ & $30^{\circ} / 15^{\circ}$ & 0.3 & $70.0 \pm 11.4$ & $4.0 \pm 1.0^{\circ}$ & $9.3 \pm 6.4$ & 0.44 & 0.66 & 53.0 & 23.5 & \\
\hline $\mathbf{M}_{4}$ & $7^{\circ}$ & $30^{\circ} / 15^{\circ}$ & 0.4 & $73.0 \pm 11.2$ & $2.7 \pm 1.5^{\circ}$ & $11.1 \pm 7.0$ & 0.45 & 0.65 & 58.6 & 6.1 & $38.6 \pm 11.7$ \\
\hline$M_{5}$ & $7^{\circ}$ & $30^{\circ} / 15^{\circ}$ & 0.5 & $79.2 \pm 15.2$ & $2.5 \pm 1.4^{\circ}$ & $10.7 \pm 10.6$ & 0.31 & 0.68 & 62.0 & 33.6 & $50.5 \pm 7.6$ \\
\hline $\mathbf{M}_{6}$ & $7^{\circ}$ & $30^{\circ} / 15^{\circ}$ & 0.6 & $83.4 \pm 18.7$ & $1.1 \pm 2.3^{\circ}$ & $12.21 \pm 12.2$ & 0.34 & 0.70 & 56.4 & 39.7 & $56.7=$ \\
\hline$\overline{S_{0}}$ & $12^{\circ}$ & $30^{\circ} / 15^{\circ}$ & None & $42.1 \pm 4.9$ & $18.8 \pm 3.1^{\circ}$ & $3.4 \pm 2.2$ & 0.34 & 0.96 & 69.9 & 36.7 & \\
\hline \multicolumn{12}{|c|}{$\begin{array}{l}\boldsymbol{\varphi}_{\mathrm{b}} \text { is décollement Strength (internal angle of friction) } \\
\boldsymbol{\varphi} \text { Sediment Strength a } \\
\boldsymbol{\varphi}_{\mathrm{ss}} \text { Sediment Strength (Strain weakened)(internal angle of friction) } \\
\boldsymbol{S} \boldsymbol{R} \text { Average Sediment rate (mm/yr) } \\
\boldsymbol{L} \text { Average Length between } \sim 3.5-7.5 \mathrm{Myr} \pm \boldsymbol{\sigma}(\mathrm{km}) \\
\boldsymbol{\alpha} \text { Taper angle } \pm \boldsymbol{\sigma} \text { (in degrees) } \\
\boldsymbol{D} \text { Average Distance between the first and second frontal thrust between } \sim 3.5-7.5 \mathrm{Myr} \\
\boldsymbol{T} \text { Average time a frontal thrust remains active between } \sim 3.5-7.5 \mathrm{Myr} \\
<\boldsymbol{R}_{\boldsymbol{o}} \%>\text { Average vitrinite reflectance of wedge between } \sim 3.5-7.5 \mathrm{Myr} \\
\boldsymbol{\%}_{0.25} \text { Proportion of }>1.5 \text { eventual } \boldsymbol{R}_{\boldsymbol{o}} \% \text { (vitrinite } \text { reflectance at } 7.5 \mathrm{Myr} \text { ) in incoming sediment at } 2.5 \mathrm{Myr} \text { at a } \\
\text { depth of } 0.75 \mathrm{~km} \text { or more from the surface. } \\
\boldsymbol{\%}_{0.75} \text { Proportion of }>1.5 \text { eventual } \boldsymbol{R}_{\boldsymbol{o}} \% \text { in incoming sediment at } 2.5 \mathrm{Myr} \text { at a depth distance of } 0.25 \mathrm{~km} \text { from the } \\
\text { surface. } \\
\lambda \text { Horizontal periodicity of eventual } \boldsymbol{R}_{\boldsymbol{o}} \% \text { in incoming sediment at } 2.5 \mathrm{Myr} \text {. }\end{array}$} \\
\hline
\end{tabular}




\section{List of Fig.}

Fig. 1: Distribution of thermal maturity for different models at $\sim 6$ Myr. Panels $A, B, C, D$ show the subduction wedges of models $W_{0}, S_{0}, M_{0}$, and $M_{0.6}$, respectively. Panel $E$ shows the variation of $R_{0} \%$ for an arbitrary horizon of reference shown by the black dashed line. The grey color of the markers indicate that no thermal maturity change in these sediments have occurred.

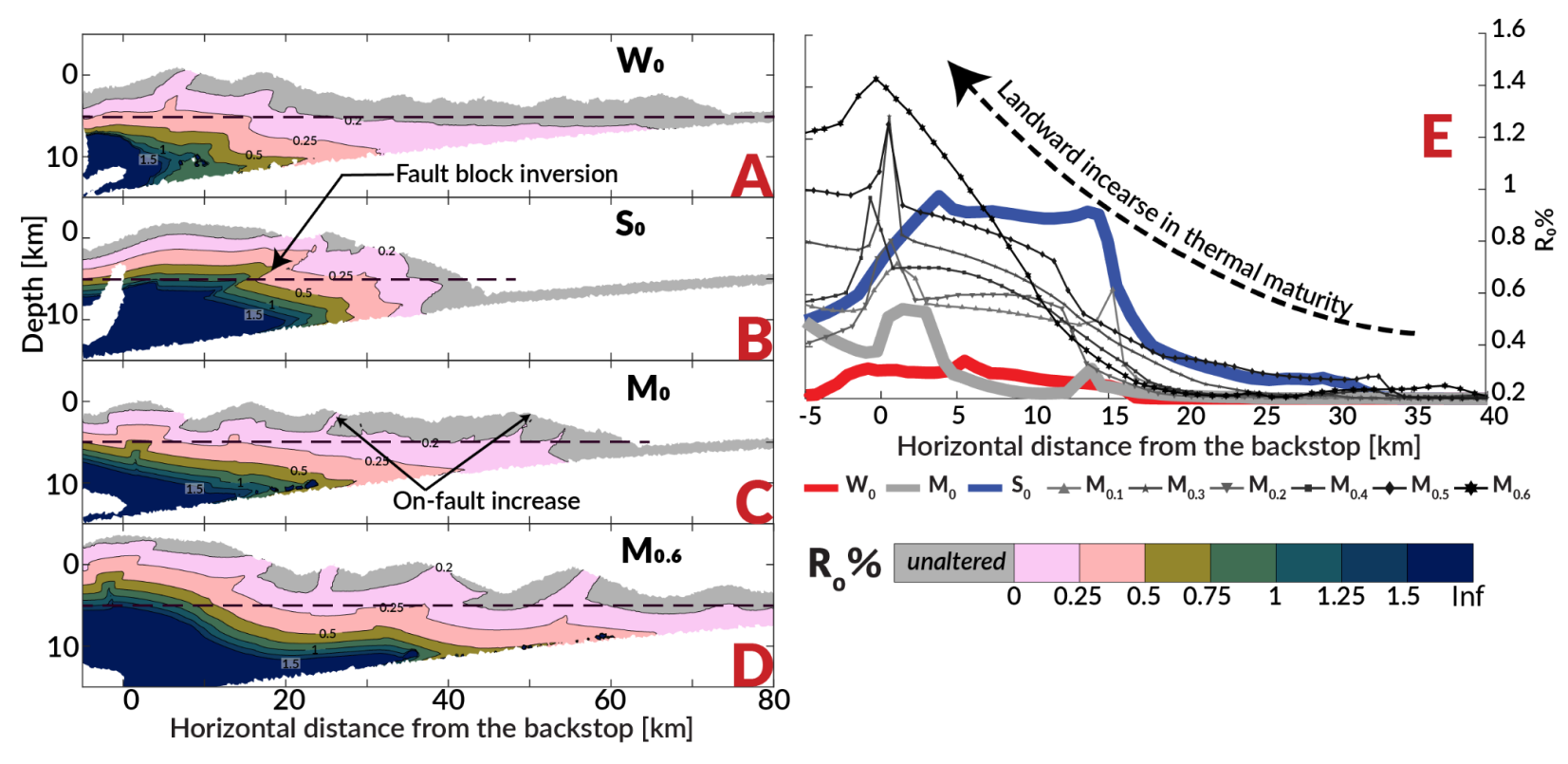


Fig. 2 Trajectory of sediments in model $\boldsymbol{W}_{\boldsymbol{0}}$ (weak décollement, no sedimentation, shaded light blue), $S_{0}$ (strong décollement, no sedimentation, shaded light yellow), $\boldsymbol{M}_{\boldsymbol{0}}$ (Medium décollement, no sedimentation, shaded light blue), $\boldsymbol{M}_{0.6}$ (Medium décollement, high sedimentation, shaded light yellow). The vertical wedge in the left shows the location of individual boreholes relative to the position of the trench at $2.5 \mathrm{Myr}$. The horizontal wedge on top of each column represents the final wedge geometry at $7.5 \mathrm{Myr}$. In each borehole A-L 10 points are plotted for their trajectories between 2.5 Myr and 7.5 Myr. The color of markers in the trajectories represent the evolution of thermal maturity on individual sediment markers while undergoing evolution. The grey color of the markers indicate that no thermal maturity change in these sediments have occurred while the black color indicates they have been eroded during the evolution of the wedge.

\section{Horizontal distance from the backstop [km]}

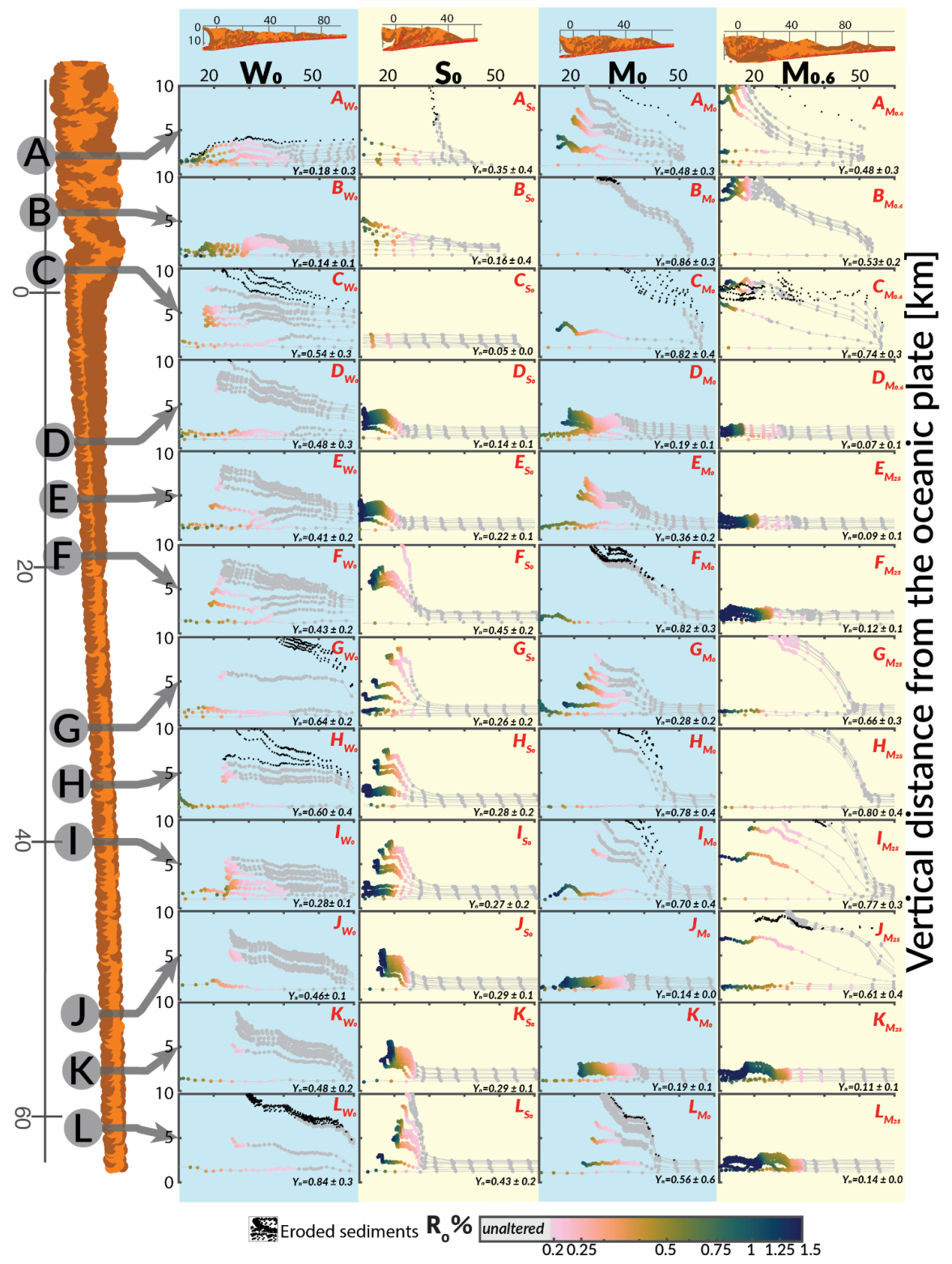


Fig: 3 Vitrinite Reflectance $\left(\boldsymbol{R}_{0} \%\right)$ vs Average depth of the trajectories normalized by the thickness of the wedge $\left(Y_{n}\right)$ for models $W_{0}, S_{0}, M_{0}$, and $M_{0.6}$ between 2.5-7.5 Myr. Individual points represent trajectory one marker in incoming sediment while the patch shows the full spread of $R_{0} \%, Y_{n}$ values.

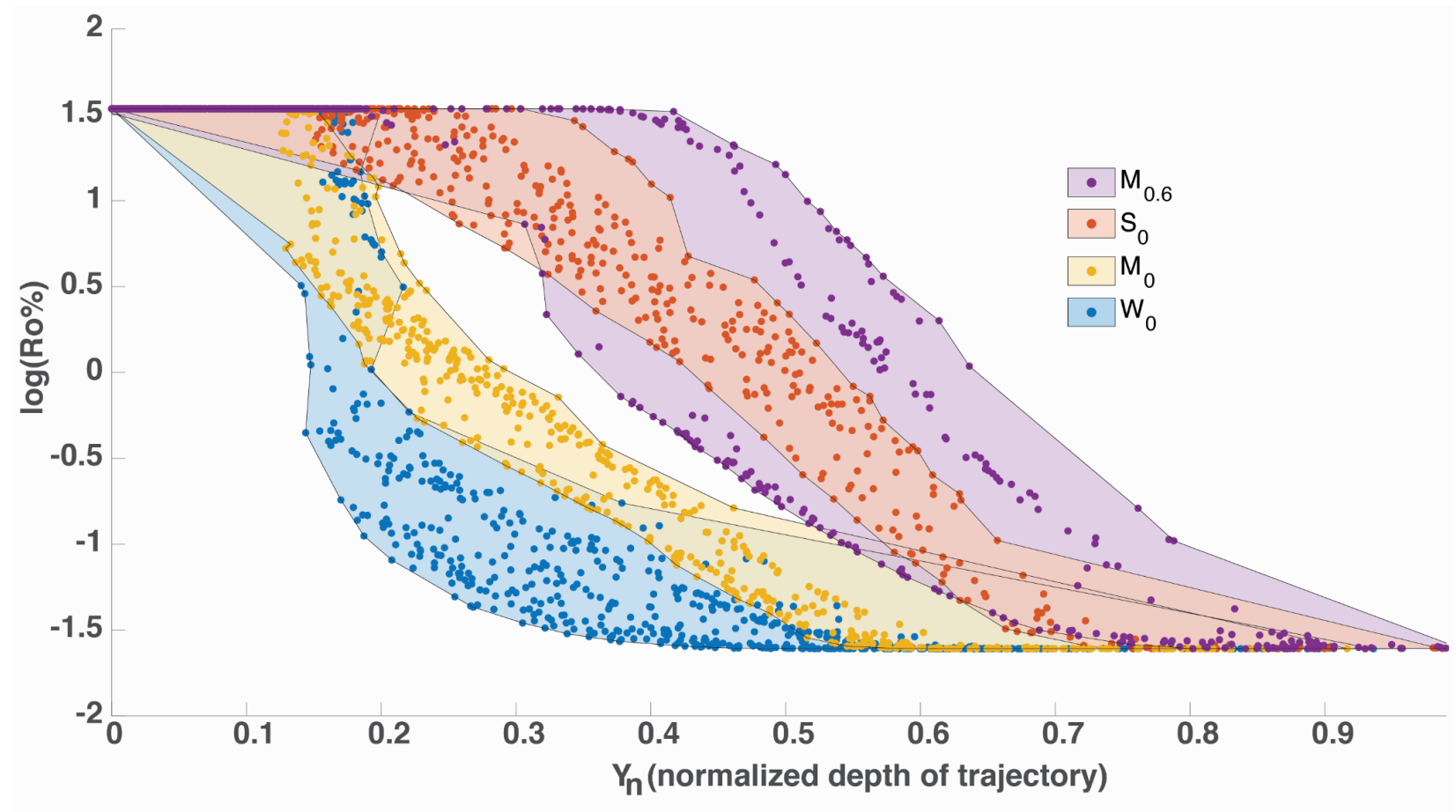


Fig. 4: Contour map of thermal maturity at 7.5 Myr mapped to sediments at 2.5 Myr. Panel A,B,C,D show the mapping for models $W_{0}, S_{0}, M_{0}, M_{0.6}$ respectively. The vertical axis (distance of sediments from the oceanic plate) has been corrected for the bending of the plate(see fig S6 for uncorrected depth). The horizontal axis represents the distance of sediments from the trench. The grey color of the markers indicate that no thermal maturity change in these sediments have occurred. To differentiate between sediments following a high and low maturity path we define an imaginary line $P_{1.5}$ (indicated by the broken yellow line) such that above the line $P_{1.5}$ all sediments take a trajectory such that the final $R_{0} \%$ is less than 1.5.

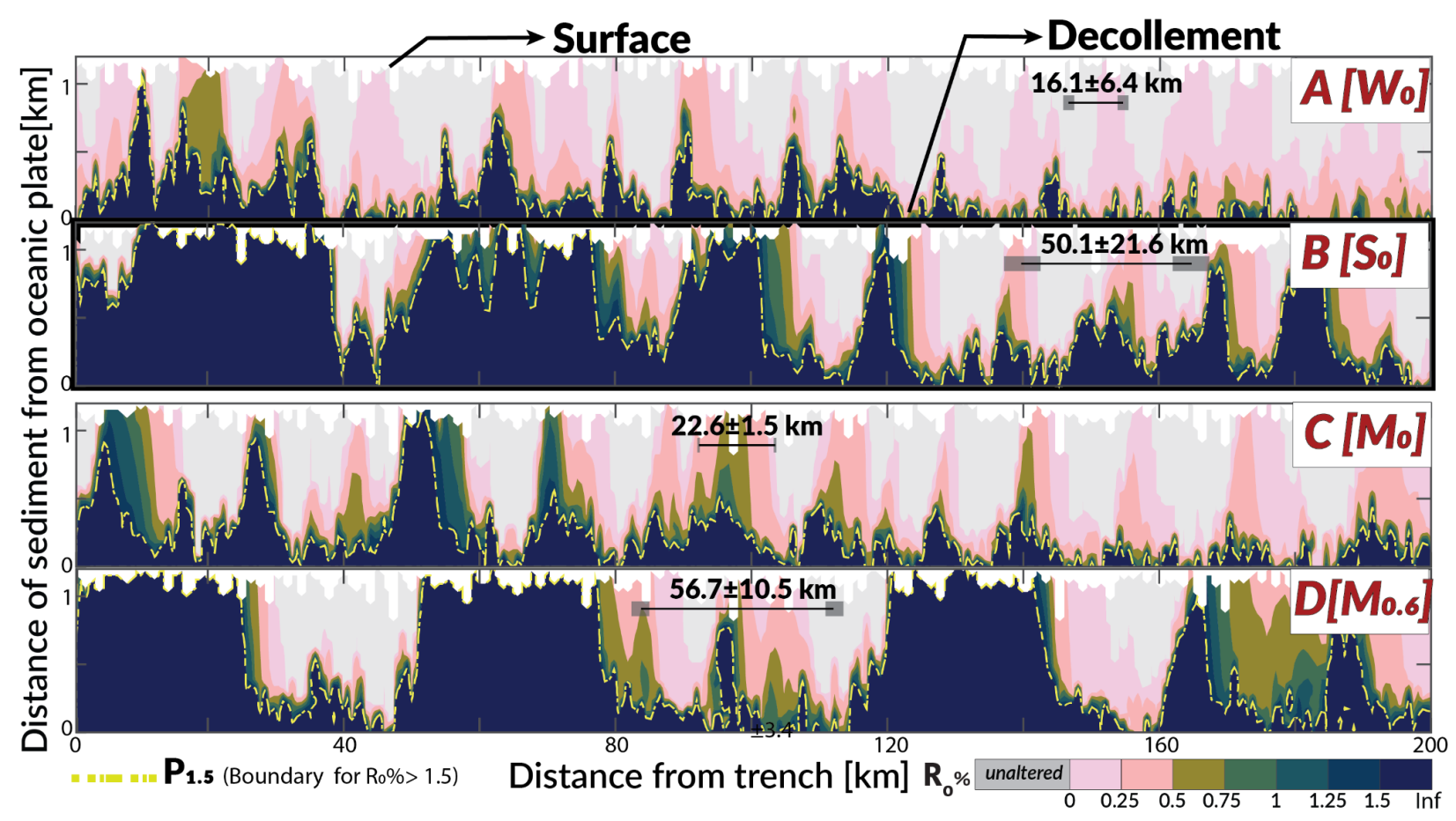


Fig. 5: Mapping of thermal maturity of markers at 7.5Myr to a frontal thrust at $\sim 4 M y r$ in model $M_{0.6}$. A. The lithology of the wedge B. The vitrinite reflectance (thermal maturity) distribution of the wedge. The half arrow represents the active frontal thrust.

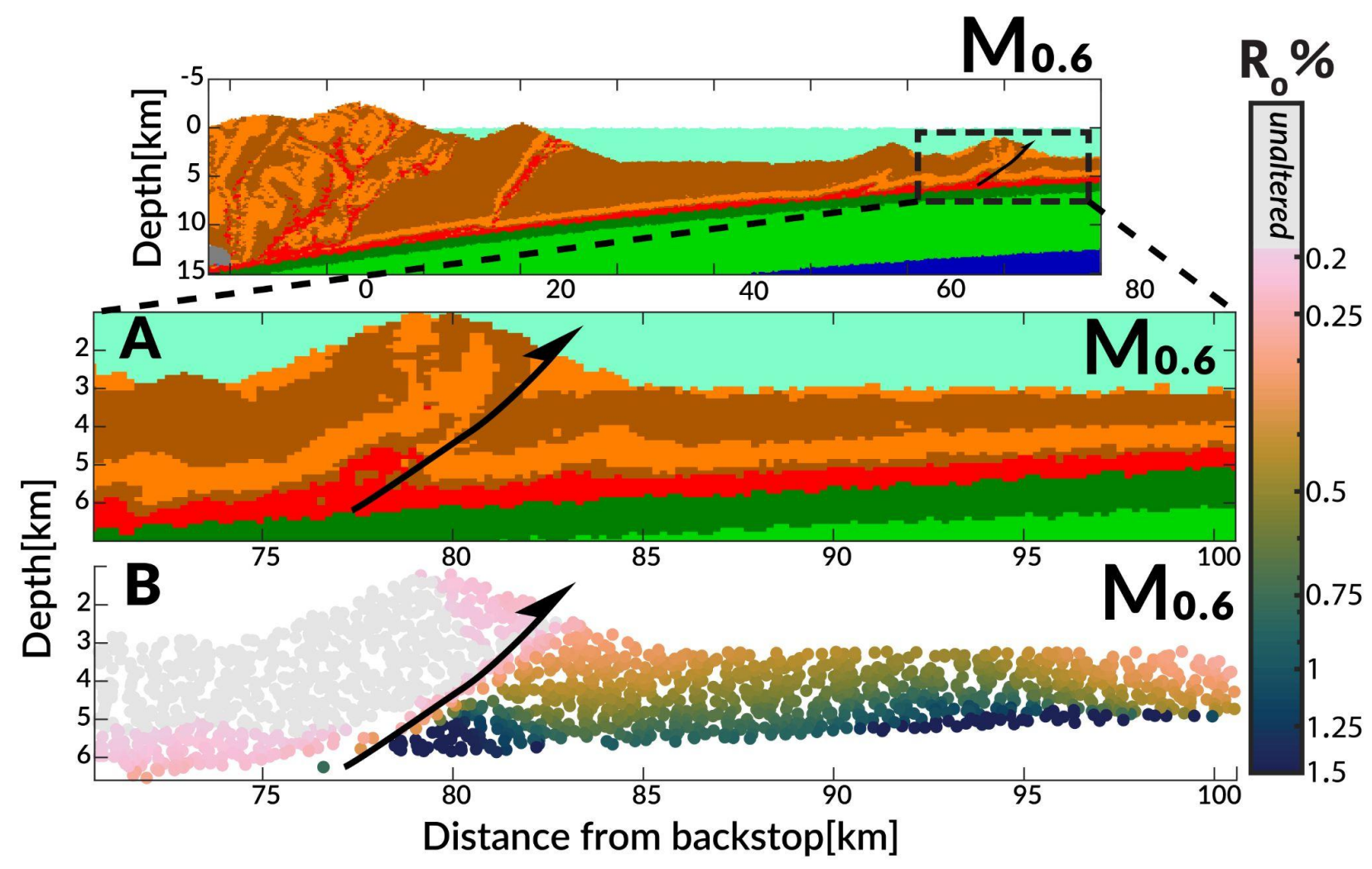


Fig. 6: Position dependency of thermal maturity preservation. Panel A. Model state at $\sim 2.5$ Myr with a thermal anomaly placed at 110-125 km from backstop B. Model state at 2.5 Myr with a thermal anomaly placed at 140-155 km from backstop. B. Model state at $\sim 7.5 \mathrm{Myr}$.

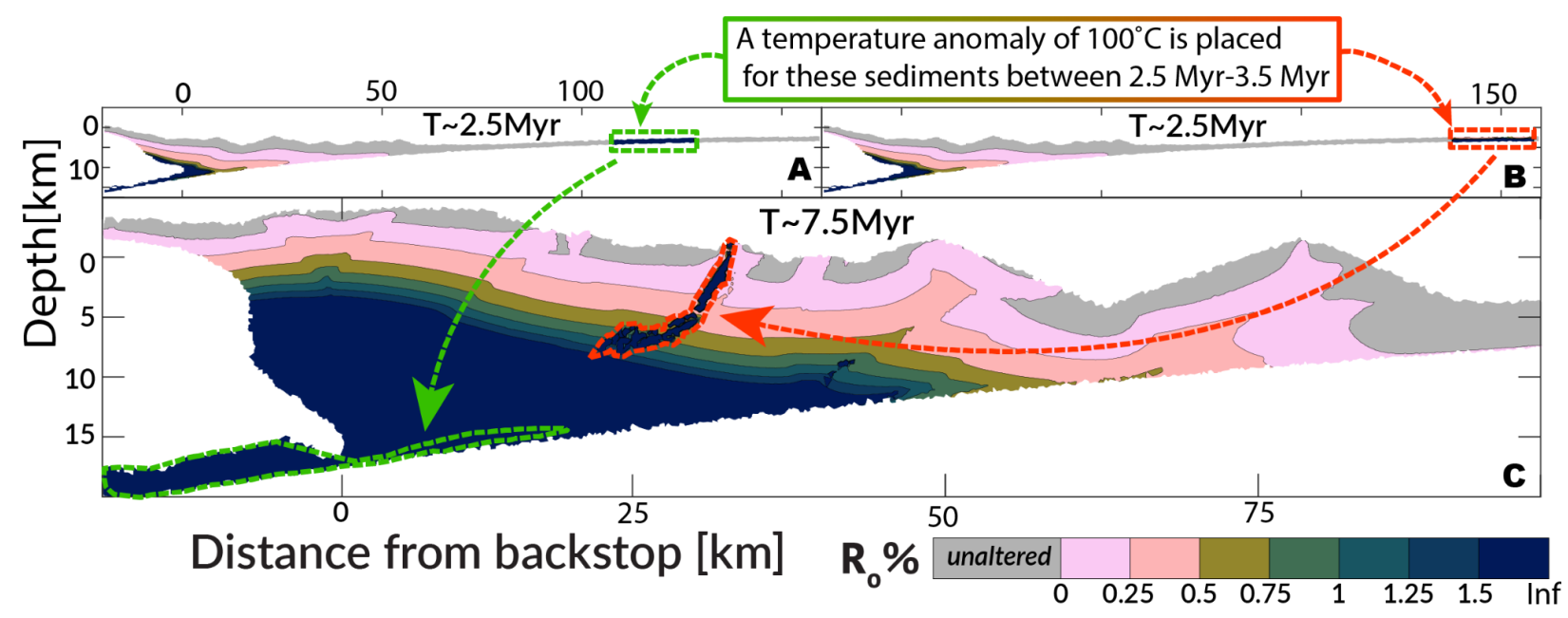




\section{Supplementary Text}

In our visco-plastic/brittle model with variable viscosity conservative finite difference ensures conservation of stresses by harmonizing the formulation of deviatoric stress across adjacent nodes. The topographic boundary in the model is simulated by an adaptive irregular surface grid coupled to the thermomechanical grid. The surface processes applied to the model are primarily implemented on this grid and are realized through the conversion of rock markers to air/water markers across this boundary, and vice-versa. Surface grid nodes can also be advected horizontally and vertically using velocities interpolated from the thermomechanical grid. As a result, both tectonic forcing and surface processes can change the model topography. Most of the sedimentation in the model happens as a cascading deposition of sediments from sea to land in subsequent basins. A free-slip boundary condition is implemented on all boundaries, except for the lower one which remains permeable to ensure mass conservation. We set thermally insulating boundary conditions on all sides except the lower one where the external thermal boundary condition is implemented.

\section{Governing equations}

The mass conservation is described by the continuity equation with the Boussinesq approximation of incompressibility as:

$\frac{\partial v_{x}}{\partial x}+\frac{\partial v_{y}}{\partial y}=0 \quad(e q .1)$

The equation for conservation of momentum with an incompressibility assumption is expressed in the 2Dstokes equation, for the $x$-axis and $y$-axis respectively, as follows:

$\frac{\partial \sigma_{x x}}{\partial x}+\frac{\partial \sigma_{x y}}{\partial y}=\frac{\partial P}{\partial x} \quad(e q .2)$

$\frac{\partial \sigma_{y y}}{\partial y}+\frac{\partial \sigma_{x y}}{\partial x}=\frac{\partial P}{\partial x}-g \rho(T, P, C, M) \quad(e q .3)$ 
where density $g \rho(T, P, C, M)$ depends on temperature $(T)$, pressure $(P)$, composition $(C)$, and mineralogy $(M)$.

The thermal equation used in the model is as follows:

$\rho C_{P} \frac{D T}{D t}=-\frac{\partial q_{x}}{\partial x}-\frac{\partial q_{y}}{\partial y}+H_{r}+H_{a}+H_{s}+H_{l} \quad(e q .4)$

where,

$$
\begin{aligned}
& q_{x}=-k(T, C) \frac{\partial T}{\partial x}, q_{y}=-k(T, C) \frac{\partial T}{\partial y} \quad(e q .5) \\
& H_{a}=T \alpha \frac{D P}{D t}, H_{s}=\sigma_{x x} \dot{\varepsilon}_{x x}+\sigma_{y y} \dot{\varepsilon}_{y y}+\sigma_{x x} \dot{\varepsilon}_{x y}
\end{aligned}
$$

where $D / D T$ is a lagrangian time derivative, and $x$ and $y$ denote the horizontal and vertical coordinates, respectively; $\sigma_{x x}, \sigma_{x y}, \sigma_{y y}$ are components of the deviatoric stress tensor; $\dot{\varepsilon}_{x x}, \dot{\varepsilon}_{y y}, \dot{\varepsilon}_{x y}$ are components of the strain rate tensor; $P$ is pressure; $T$ is temperature; $q_{x}$ and $q_{y}$ are the components of heat flux in horizontal and vertical direction; $\rho$ is density; $g$ is the gravitational acceleration; $C_{P}$ is the isobaric heat capacity; $H_{r^{\prime}} H_{a^{\prime}} H_{s^{\prime}} H_{l^{\prime}}$ denote, the radioactive, adiabatic, shear and latent heat production, respectively. $k(T, C)$ is the thermal conductivity, a function of composition, depth, and temperature(Table 1). To match the empirical relationship between depth and thermal conductivity, as measured on core samples in the borehole at IODP Site C0002(Sugihara et al., 2014; Tobin et al., 2015). To simulate the decrease in thermal conductivity near the surface caused by increased porosity, we modify the thermal conductivity formulation for sediments as a function of temperature and depth as follows 


$$
k_{\text {sed }}=0.96+\frac{807}{T+77}\left(1-e^{\frac{-Z^{2}}{1.3 e^{7}}}\right)
$$

For décollement we again use a similar relationship however with a larger thermal conductivity near the surface to emulate higher heat transfer in shear zones due to fluid advection

$$
k_{\text {sed }}=1.5+\frac{807}{T+77}\left(1-e^{\frac{-Z^{2}}{1.3 e^{7}}}\right)
$$

\section{Rheological model}

The expression for effective creep viscosities $\left(\eta_{e f f}\right)$ of the materials used in the model is determined from experimental data(Ranalli, 1995) using a calibrated parameterized function of pressure $(P)$ and temperature $(T)$, known as flow law (Table 1$)$.

$\eta_{e f f}=F\left(\dot{\varepsilon}_{I I}\right)^{1-n} A_{D} \frac{-1}{n} h^{m} \exp \left(-\frac{E_{a}+V_{a} P}{n R T}\right) \quad(e q .7)$

where, $F$ is a dimensionless constant that depends on the type of experiments used for calibration, $P$ is pressure (Pa), $T$ is the temperature $(\mathrm{K}), R$ is the gas constant $(8.314 \mathrm{~J} / \mathrm{K} / \mathrm{mol}), \mathrm{h}$ is grain size $(\mathrm{m})$ and $\mathrm{A}_{\mathrm{D}}$, $\mathrm{n}, \mathrm{m}, \mathrm{E}_{\mathrm{a}}$ and $\mathrm{V}_{\mathrm{a}}$ are experimentally determined rheological parameters: $A_{D}$ is the material constant $\left(\mathrm{Pa}^{-\mathrm{n}} \mathrm{s}^{-1} \mathrm{~m}^{-\mathrm{m}}\right), \mathrm{n}$ is the stress exponent, $\mathrm{m}$ is the grain size exponent, $\mathrm{E}_{\mathrm{a}}$ is activation energy $(\mathrm{J} / \mathrm{mol})$ and $\mathrm{V}_{\mathrm{a}}$ is activation volume $(\mathrm{J} / \mathrm{Pa})$. As dislocation creep does not depend on grain size therefore we assume $h^{m}=1 . \dot{\varepsilon}_{I I}$ is the second invariant of strain tensor computed as

$$
\dot{\varepsilon}_{I I}=\sqrt{\frac{\dot{\varepsilon}_{i j} * \dot{\varepsilon}_{i j}}{2}} \quad(e q .8)
$$


The model uses visco-plastic rheology to account for both brittle rheology of the shallower and colder rigid lithosphere and deeper, hotter ductile lithosphere and asthenosphere. Using the Mohr-Coulomb failure criterion we limit effective viscosity as

$\eta_{e f f} \leq \frac{c+P \sin (\varphi)}{2 \dot{\varepsilon}_{I I}} \quad(e q .9)$

Where, $c$ is cohesion and $\varphi$ is an effective internal angle of friction or $\mu=\tan (\varphi)$ where $\mu$ is the coefficient of internal friction.

\section{Boundary Conditions}

A free-slip boundary condition is implemented on all boundaries, except on the lower boundary, where is passable in the vertical direction. Where we implement, an external free slip condition similar to (Burg and Gerya, 2005) where a free slip condition is satisfied at an external boundary such that

$$
\frac{\partial V_{x}}{\partial x}=0, \frac{\partial V_{y}}{\partial y}=\frac{V_{y}}{\Delta Y_{\text {external }}}
$$

wWhere, $V_{x}$ and $V_{y}$, are the velocities in the horizontal and vertical directions at the boundary, $\Delta Y_{\text {external }}$ is the depth that lies outside the modeling domain, and where free slip condition is maintained. Similarly, we set thermally insulating boundary conditions on all sides except the lower one where the external thermal boundary condition is implemented.

\section{Surface Processes}

The rock-water/air boundary is simulated by an adaptive irregular grid that is advected horizontally and vertically and is coupled to the thermomechanical grid which controls the tectonic change of the surface. Apart from the tectonic changes, surface processes prescribed in 
the model can also change the topography. The surface process in the model is controlled by conversion of rock markers to air/water and vice versa. All sedimentation in the model happens as a focused deposition of sediments from sea to land in morphological depressions (e.g. trench) is modelled as follows (Figure S2)

$$
\begin{aligned}
& Y_{\text {new }}=Y_{\text {old }}+K \bullet Y_{\text {fill }} \\
& \text { Where, } K=\min \left(\frac{V_{\text {budget }}}{V_{\text {basin }}}, 1\right)
\end{aligned}
$$

Due to the arbitrary shape of the basin, filling the basin using the above equation can overfill /underfill in a specific step. However, we compute the volume of the sediments that have been deposited and balance out the sediment deficit/overfill in the next step. Therefore over long run the sedimentation amount remains equivalent to the prescribed amount.

\section{Limitations}

For instance, even with a minimum grid size of $150 \mathrm{~m}$ x $500 \mathrm{~m}$, the model is not able to simulate very narrow faults that usually occur in nature and lead to a very local increase in thermal maturity. Therefore, while the thermal maturity anomaly observed in the borehole can be concentrated at the site of the fault which can be only a few centimeters wide, thermal maturity for our model can be spread over several hundred meters (Fig. 7). Wider faults also result in a smaller characteristic time for local heat diffusion, meaning the rise in temperature due to viscous heating in faults is sustained for a smaller period. Consequently, in our models, the relative rise in thermal maturity of sediments in faults is far less compared to the observations in the borehole. This problem could be resolved in the future using adaptive gridding, where one can temporarily increase the resolution in zones with high strain rates, leading to much narrower faults and concentrated elevation of heat and maturity in faults. 
Another assumption in our model is that the model does not contain compaction or an increase in sediment strength with increasing depth and thickness of the wedge. Although this was done to keep the model simple, in the future one can introduce an empirical increase in material strength both with depth and seaward to landward. Additionally, thermal maturity which is related to porosity by (Schmoker and Gautier, 1988) can also be used to give a measure of compaction in the wedge and could be linked to material strength. However, one needs to be careful while implementing this relationship as fault zones which generally have a higher thermal maturity due to viscous heating tend to have lower strength. We have also not considered the influence of fluid flow in our models, which can have a significant impact on the maturity value, especially in the fault zones. However, to mimic this effect we used elevated values of conductivity for the weak material present in the décollement. 


\section{List of Supplementary figures.}

Fig. S1: Initial model setup. A. The lithological and geothermal map of the whole computational domain with boundary conditions. B. The zoomed lithological and geothermal map of the inset illustrates the junction of continental and oceanic plates. The colors represent different lithology of the materials used in the models, with upper and lower crust represented by light and dark grey, upper and lower oceanic crust represented by dark and light green. The arrows around the computational domain represent the imposed boundary conditions, while the white contour lines(dashed in the zoomed panel) show the geothermal gradients used for the initial model. The numbers on the white contour lines represent the temperature values in ${ }^{\circ} \mathrm{C}$ for the contour.

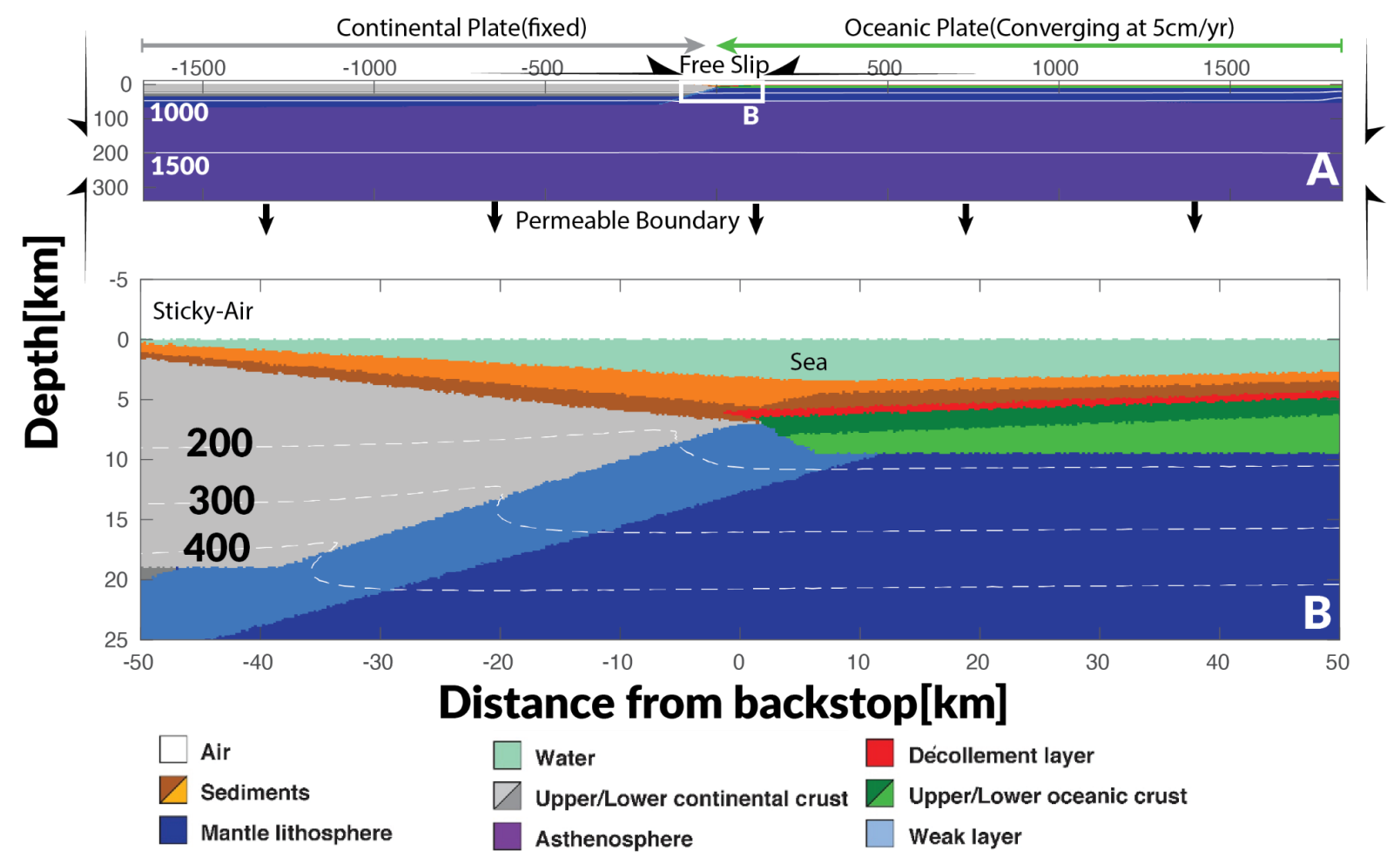


Fig. S2: Plot of Temperature vs Depth profile in all reference models $W_{0}, M_{0}, S_{0}$ compared to Temperature-depth profile based on in-situ temperature from the long-term borehole monitoring system (indicated blue path is the range of temperature estimated by (Sugihara et al., 2014))

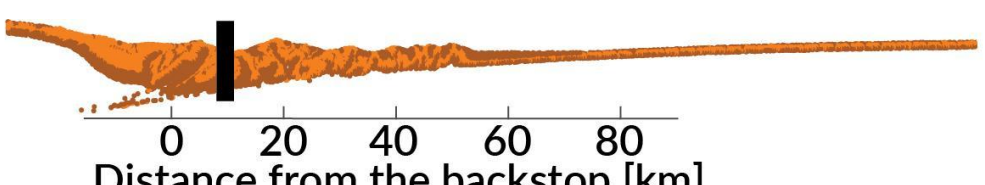

Distance from the backstop [km]

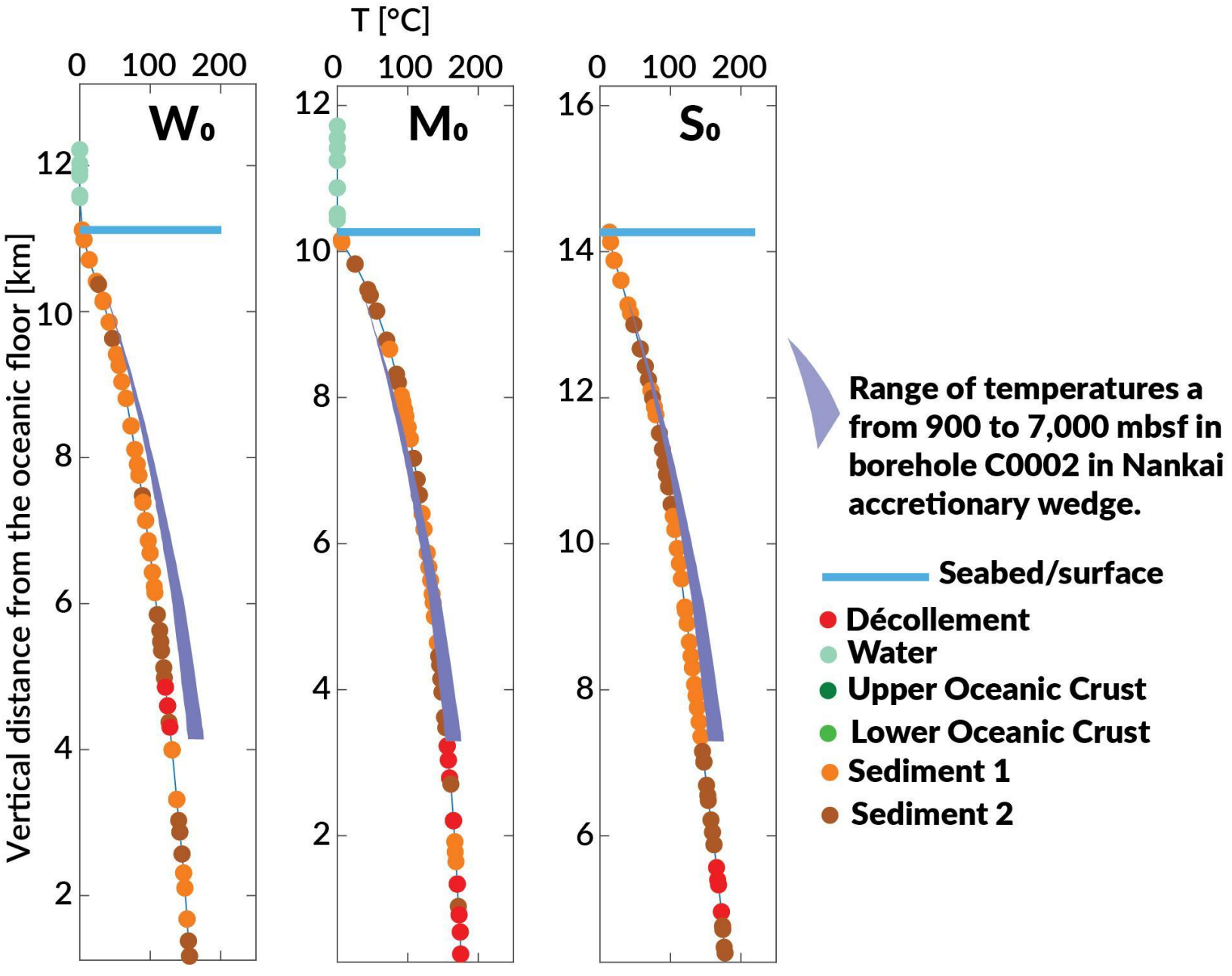


Fig. S3: Scheme of trench sedimentation in models (taken from (Mannu et al., 2017)).

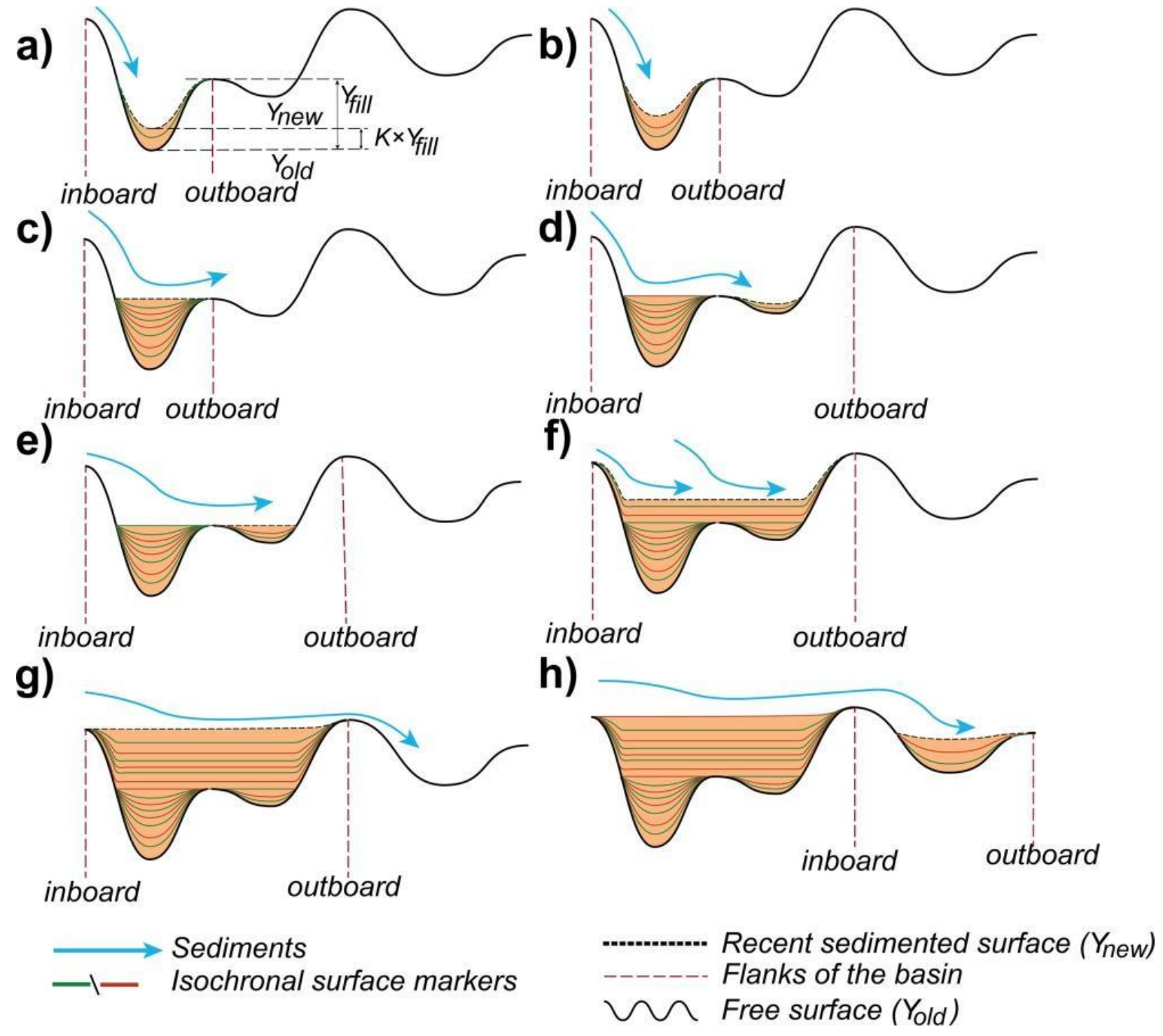


Fig. S4: Comparison of vitrinite reflectance distribution with P-Wave velocity structure for accretionary wedges. Panels $A, B, C, D$ show the thermal maturity for subduction wedges of models $W_{0}, S_{0}, M_{0}$, and $M_{0.6}$, respectively. E,F,G show the Vp structure for northern Hikurangi margin offshore Gisborne, New Zealand (Arai et al., 2020), Nankai margin offshore Cape Ashizuri, Shikoku,Japan (Nakanishi et al., 2018) and Eastern nankai Margin offshore Tokai (Górszczyk et al., 2019)respectively.

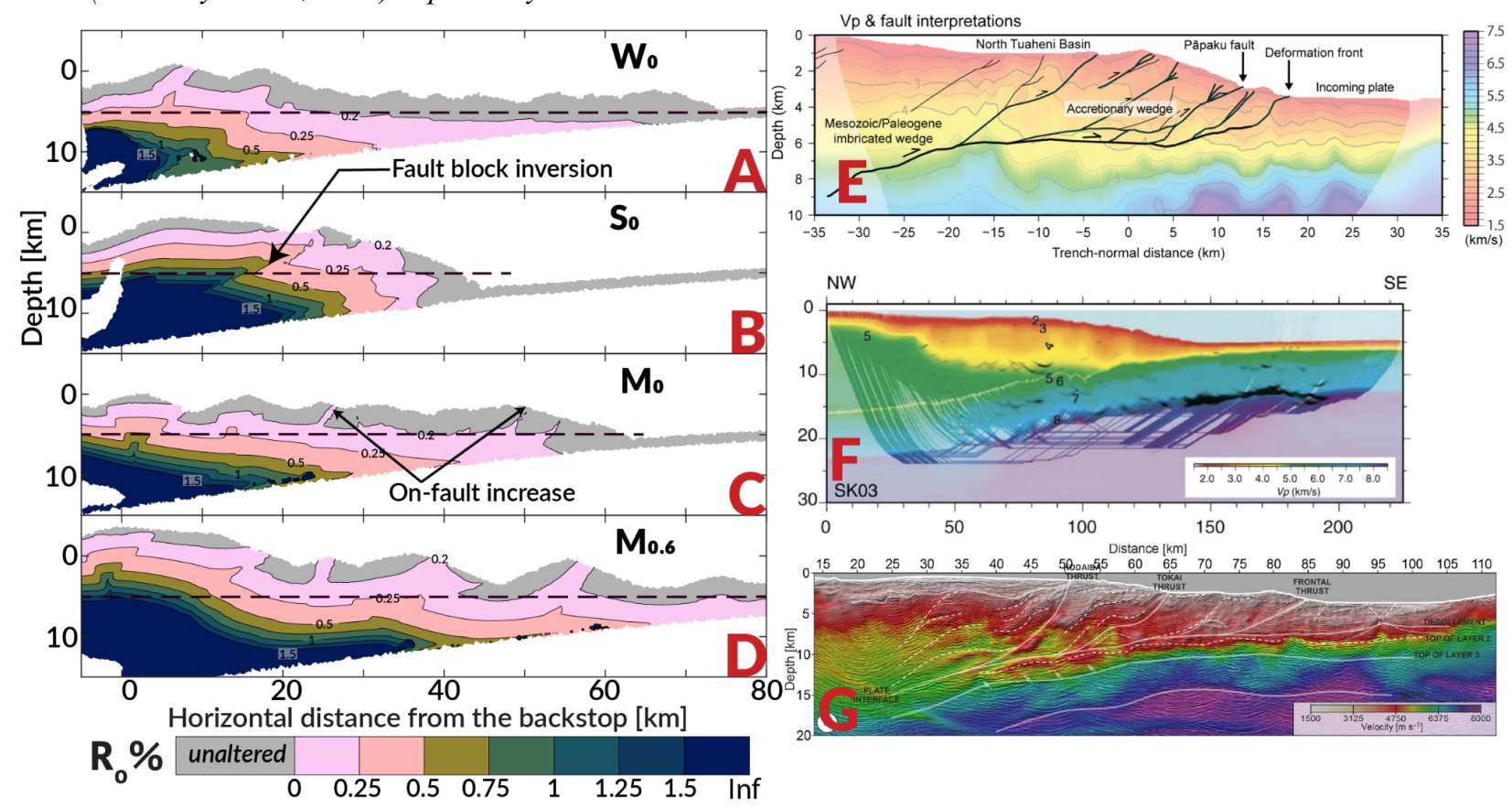

